OPEN ACCESS

Edited by:

Xing Li Wang,

Novartis, United States

Reviewed by:

Agnieszka Barbara Najda,

University of Life Sciences of Lublin,

Poland

Chi Chien Lin,

National Chung Hsing University,

Taiwan

*Correspondence:

Zong-Gen Peng

pumcpzg@126.com

Specialty section:

This article was submitted to Inflammation Pharmacology,

a section of the journal

Frontiers in Pharmacology

Received: 19 January 2021

Accepted: 10 March 2021

Published: 15 April 2021

Citation:

Wang X-K and Peng Z-G (2021)

Targeting Liver Sinusoidal Endothelial

Cells: An Attractive Therapeutic

Strategy to Control Inflammation in

Nonalcoholic Fatty Liver Disease.

Front. Pharmacol. 12:655557.

doi: 10.3389/fphar.2021.655557

\section{Targeting Liver Sinusoidal Endothelial Cells: An Attractive Therapeutic Strategy to Control Inflammation in Nonalcoholic Fatty Liver Disease}

\author{
Xue-Kai Wang ${ }^{1}$ and Zong-Gen Peng ${ }^{1,2,3 *}$ \\ ${ }^{1}$ CAMS Key Laboratory of Antiviral Drug Research, Institute of Medicinal Biotechnology, Chinese Academy of Medical Sciences \\ and Peking Union Medical College, Beijing, China, ${ }^{2}$ Key Laboratory of Biotechnology of Antibiotics, National Health and Family \\ Planning Commission, Institute of Medicinal Biotechnology, Chinese Academy of Medical Sciences and Peking Union Medical \\ College, Beijing, China, ${ }^{3}$ Beijing Key Laboratory of Antimicrobial Agents, Institute of Medicinal Biotechnology, Chinese Academy \\ of Medical Sciences and Peking Union Medical College, Beijing, China
}

Nonalcoholic fatty liver disease (NAFLD), especially its advanced stage nonalcoholic steatohepatitis $(\mathrm{NASH})$, has become a threatened public health problem worldwide. However, no specific drug has been approved for clinical use to treat patients with $\mathrm{NASH}$, though there are many promising candidates against NAFLD in the drug development pipeline. Recently, accumulated evidence showed that liver sinusoidal endothelial cells (LSECS) play an essential role in the occurrence and development of liver inflammation in patients with NAFLD. LSECs, as highly specialized endothelial cells with unique structure and anatomical location, contribute to the maintenance of liver homeostasis and could be a promising therapeutic target to control liver inflammation of NAFLD. In this review, we outline the pathophysiological roles of LSECs related to inflammation of NAFLD, highlight the pro-inflammatory and anti-inflammatory effects of LSECs, and discuss the potential drug development strategies against NAFLD based on targeting to LSECs.

Keywords: nonalcoholic fatty liver disease, liver sinusoidal endothelial cell, inflammation, capillarization, endothelial dysfunction, therapeutic strategy

\section{INTRODUCTION}

Nonalcoholic fatty liver disease (NAFLD), now proposed changing to metabolic-associated fatty liver disease (MAFLD), has gradually become one of the most common liver diseases in the world (Younossi et al., 2016; Eslam et al., 2020). Technically, NAFLD is divided into nonalcoholic fatty liver (NAFL) and nonalcoholic steatohepatitis (NASH) according to pathological conditions (Stefan et al., 2019). The main feature of NAFL is at least $5 \%$ of liver steatosis without hepatocyte damage in the form of hepatocyte ballooning, whereas NASH mainly manifests more than $5 \%$ of liver steatosis with inflammation and hepatocyte damage (Stefan et al., 2019). Typically, NASH is often accompanied with liver fibrosis and may highly develop into cirrhosis and even hepatocellular carcinoma (Younossi, 2019). In recent years, NASH has gradually become a leading cause of liver transplantation among adults in European and American countries (Wong et al., 2015; Estes et al., 2018; Younossi, 2019). However, despite the high incidence and severity of NASH, no specific drug is currently approved and existing treatment methods are only aimed at symptomatic treatment rather than mechanism-based (Friedman et al., 2018). 
Inflammation is one of the major engines of $\mathrm{NASH}$ progression (Schuster et al., 2018). Although a moderate and resolved inflammatory response contributes to homeostasis remodeling and tissue repair and thereby has hepatoprotective effects, inflammation in NASH is persistent, which leads to hepatocyte death and liver parenchymal damage (Brenner et al., 2013). Furthermore, uninterrupted low-level inflammation can cause hepatic stellate cells (HSCs) to activate and differentiate into myofibroblasts. The activated myofibroblasts release a large amount of extracellular matrix, which are rich in collagen fibers, to extracellular space and eventually result in hepatic fibrosis or cirrhosis (Schuster et al., 2018; Schwabe et al., 2020). Therefore, understanding the mechanisms of occurrence and development of inflammation in NASH is of the utmost importance for better controlling inflammation, which is essential to prevent, alleviate, and even reverse fibrosis.

Vascular endothelium is located at the junction of circulating blood and peripheral tissues. In addition to acting as a physical barrier, vascular endothelium participates in various pathophysiological processes, including inflammation, angiogenesis, vascular tone regulation, platelet function regulation, and metabolic homeostasis (Chiu and Chien, 2011; Pi et al., 2018). Hepatic sinusoidal endothelium, as a physical barrier controlling material exchanges between liver parenchyma and circulation, is constituted of liver sinusoidal endothelial cells (LSECs) which are highly specialized endothelial cells and the most abundant liver non-parenchymal cells (Brunt et al., 2014). Due to their unique anatomical location, LSECs play a critical role in the pathophysiological activities of the liver. Recently accumulated evidence showed that LSECs play an essential role in the occurrence and progression of liver inflammation in NAFLD. In this review, we briefly summarize the pathophysiological role of LSECs related to liver inflammation, highlight the occurrence and development mechanisms of inflammation of NAFLD associated with LSECs, and finally discuss the potential drug development strategies against NAFLD based on targeting to LSECs.

\section{THE STRUCTURE AND BIOLOGICAL FUNCTION OF LIVER SINUSOIDAL ENDOTHELIAL CELLS}

Due to their unique structure and anatomical location, LSECs play important physiological roles in the maintenance of liver homeostasis, including substance exchange, blood flow regulation, high endocytic capacity, and immune regulation.

\section{Unique Structure and Biological Function of Liver Sinusoidal Endothelial Cells in Substance Exchange}

LSECs are unique in structure and function distinguished from other liver vascular endothelial cells. From an evolutionary point, the hepatic sinusoids are derived from the capillary vessels of the septum transversum and have a fenestrated phenotype acquired during 10 and 20 gestation weeks, which are different from the portal vessels that are developed from the vitelline veins (Gouysse et al., 2002; Geraud et al., 2017). In terms of structure and function, the specificity of LSECs is an adaptation to local microenvironment determined by anatomical location (Potente and Makinen, 2017). LSECs are located at an interface between the liver parenchyma and the mixed blood from the hepatic artery (30\%) and portal vein (70\%) (Poisson et al., 2017). On the sinusoidal side, LSECs are exposed to substances circulated in the blood, such as abundant nutrients, hormones, bile acids, and oxygen. While on the abluminal side, LSECs directly communicate with HSCs and hepatocytes that are critical for glycolipid metabolism. Therefore, the distinguished location feature assigns LSECs with the possibility of excellent substance exchange capacity (Poisson et al., 2017). Under normal conditions, LSECs have hallmarks characterized as the fenestrated phenotype, lack of basement membrane, and absence of diaphragm (Figure 1), and the unique structure made LSECs the most permeable endothelial cells in mammals, which is of significance for achieving more substance exchanges between liver parenchyma and blood to better match the metabolic function of the liver (Poisson et al., 2017). The fenestrae of LSECs, with a diameter of $50 \sim 150 \mathrm{~nm}$, connects the space of Disse with the sinusoidal side, allowing lipoproteins, chylomicron remnants (a small lipoprotein with a diameter of about 30 80 nm that is decomposed by chylomicrons by lipoprotein lipase on the endothelial membrane of peripheral capillaries), and other macromolecules to enter the space of Disse from the circulating blood and then to be utilized by hepatocytes (Carpenter et al., 2005; Hilmer et al., 2005; Cogger et al., 2006). Besides, LSEC's fenestrae are organized in clusters termed as sieve plates, in which the size and number of fenestrae vary in different positions and can be changed dynamically depending on physiological states such as fasting or pathological states (Wisse et al., 1985; O’Reilly et al., 2010; Xie et al., 2010; DeLeve, 2015; Monkemoller et al., 2015; Zapotoczny et al., 2019). Overall, due to their location features, structural changes, and high permeability, LSECs establish a differential and selective barrier that can be adjusted according to the changes of pathophysiological environment.

\section{Regulation of Liver Sinusoidal Endothelial Cells in Blood Flow}

As endothelial cells, LSECs also play a role in regulating blood flow. Nitric oxide (NO) and endothelin-1 (ET-1), mainly produced by LSECs under normal conditions, are the two most powerful vasoactive substances in the liver, which causes dilation and contraction of blood vessels, respectively (Rieder et al., 1991; Shah et al., 1997). Under physiological conditions, in responding to the shear stress that is a friction between the vascular endothelium and blood flow, LSECs increase NO production and down-regulate ET-1 expression, which are mediated by Kruppel-like factor 2 (KLF2), an endothelialspecific transcription factor and a crucial anti-angiogenic factor (Davies, 1995; Shah et al., 1997; Parmar et al., 2006; Zeng et al., 2015). Meanwhile, healthy LSECs maintain HSCs 


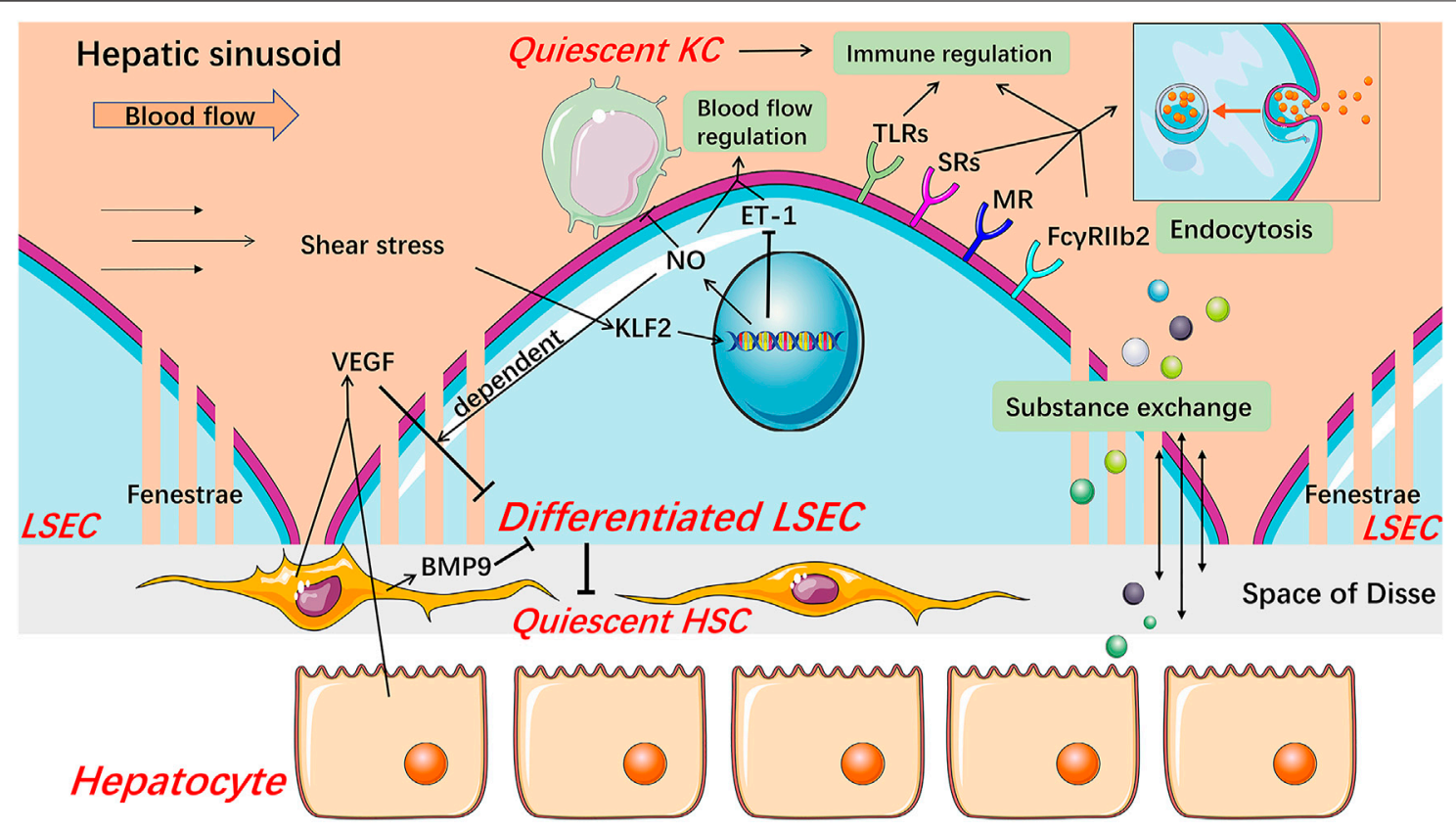

FIGURE 1 | Structure and major physiological function of LSECs. Healthy differentiated LSECs, characterized by the fenestrated phenotype and lack of basement membrane, are located at the junction of circulating blood and liver parenchyma, which state is maintained by VEGF from hepatocytes and HSCs in an LSEC-derived NO-dependent manner and BMP9 from HSCs. LSECs increase NO production and reduce ET-1 expression through KLF2 in response to the shear stress in hepatic sinusoids, thereby regulating blood flow. NO also keeps KCs and HSCs quiescent. LSECs fenestrae constitute a sieve plate that makes LSECs highly permeable to better exchange substance between liver parenchyma and blood. The expression of SRs, MR, and FcyRlllb2 endows LSECs with high endocytic capacity. These receptors, along with TLRs, are related to the immunoregulatory function of LSECs which contributes to the immune clearance and antigen presentation of LSECs. BMP9 Bone morphogenetic protein 9, ET-1 endothelin-1, FcpRllb2 Fc gamma-receptor llb2, HSC hepatic stellate cell, KC Kupffer cell, KLF2 Kruppel-like factor 2, LSEC liver sinusoidal endothelial cell, MR mannose receptor, NO nitric oxide, SRs scavenger receptors, TLRs Toll-like receptors, VEGF vascular endothelial growth factor.

and Kupffer cells (KCs) quiescence through NO-dependent pathways (Deleve et al., 2008; Tateya et al., 2011). These results indicate that LSECs may participate in inflammation and fibrosis under pathological conditions via $\mathrm{NO}$ signaling. Besides, carbon monoxide and the metabolites of the cyclooxygenase pathway, such as prostacyclin, are also associated with the regulation of blood flow in the hepatic sinusoids (Fernandez, 2015). Therefore, this regulation process involved with LSECs not only copes with the circadian change of hepatic blood flow mainly caused by digestion but also participates in maintaining the hepatic homeostasis, including inhibiting the occurrence of inflammation and fibrosis under pathophysiological condition.

\section{High Endocytic Capacity of Liver Sinusoidal Endothelial Cells}

LSECs possess the strongest potential ability of endocytosis in the human body, which is also an outstanding feature of LSECs (Smedsrod et al., 2009). Based on the dual-cell principle of waste clearance, the cells responsible for cleaning up circulating waste are divided into two types. One is professional phagocytes represented by macrophages which mainly clean up larger particles $(>0.5 \mu \mathrm{m})$ by phagocytosis. The other is professional pinocytes represented by the scavenger endothelial cells, including LSECs, which are responsible for cleaning soluble macromolecules and smaller particles by endocytosis (Sorensen et al., 2012). Accordingly, LSECs express a variety of endocytosis receptors, including scavenger receptor (SR), mannose receptor (MR), and $\mathrm{Fc}$ gamma-receptor IIb2 (Fc $\gamma$ RIIb2). SRs, including SR-A, SR-B, and SR-H (stabilin-1 and stabilin-2), are expressed on normal LSECs, and stabilin-1 and stabilin-2 are thought to play a major role (Hughes et al., 1995; McCourt et al., 1999; Zhou et al., 2000; Adachi and Tsujimoto, 2002; Malerod et al., 2002; Politz et al., 2002; Hansen et al., 2005; Sorensen et al., 2012). Stabilin-1 and stabilin-2 mediate uptake and degradation of modified proteins and lipoproteins such as advanced glycation-end products-albumin and oxidized low-density lipoproteins (oxLDL), extracellular matrix macromolecules, protein turnover by-products including hyaluronan, heparin, and chondroitin sulfate (Sorensen et al., 2012). MR mediates the uptake of a wide range of endogenous glycoproteins and microbial glycans, the recruitment of lysosomal enzymes, and the endocytosis of other tissue turnover waste products including collagen alpha chains, tissue plasminogen activator (Stahl and Ezekowitz, 1998; Lee et al., 2002; McGreal et al., 2004; Sorensen et al., 2012). In particular, the expression and activity of MR in the liver are regulated by inflammatory stimuli and some cytokines. For example, interleukin (IL)-1 increases the expression of MR in LSECs while IL-10 reduces the activity of the receptor, therefore, MR might be involved in immunity and regulation of 
glycoprotein homeostasis (Knolle et al., 1998; Arteta et al., 2010). Fc $\gamma$ RIIb2, the only Fc gamma-receptor in LSECs, is dedicated to ingesting small soluble immune complexes and cleaning up circulating IgG immune complexes along with KCs (Hebert, 1991; Johansson et al., 1996; Mousavi et al., 2007; Sorensen et al., 2012).

\section{Immune Regulation of Liver Sinusoidal Endothelial Cells}

LSECs are continuously exposed to food and microbial antigens, which come from the gastrointestinal tract and enter hepatic sinusoids through the portal vein (Kubes and Jenne, 2018). As hepatic immune gatekeepers, LSECs maintain a hepatic immune tolerance environment and immune response to cope with other foreign pathogens and thus keep the liver from being damaged by unnecessary immune responses (Kubes and Jenne, 2018; Shetty et al., 2018). Recent studies showed that LSECs participate in both innate and adaptive immune regulation. Pattern recognition receptors including the Toll-like receptor (TLR) family, along with endocytosis receptors, assign LSECs with an ability to recognize and ingest foreign antigens (Chen and Nunez, 2010; Wu et al., 2010; Shetty et al., 2018). Furthermore, LSECs can still respond to signals mediated by these receptors even in the liver immune tolerance environment, though the activation of TLRs in LSECs is relatively limited compared to classical antigenpresenting cells (Wu et al., 2010; Shetty et al., 2018). Besides, endocytosis receptors on LSECs also play an important cellspecific role through interaction with TLRs and regulation of inflammation-related signals (Canton et al., 2013; Shetty et al., 2018). In adaptive immunity, LSECs can cross-present antigen to $\mathrm{CD}^{+} \mathrm{T}$ cells by using SRs and induce tolerant naive $\mathrm{CD} 8^{+} \mathrm{T}$ cells through enhanced interaction between programmed cell death one ligand one on LSECs and programmed cell death protein one on $\mathrm{CD}^{+} \mathrm{T}$ cells (Limmer et al., 2000; Limmer et al., 2005; Burgdorf et al., 2007; Diehl et al., 2008; Shetty et al., 2018). Certainly, when faced with harmful pathogen stimulation, LSECs can also effectively drive $\mathrm{T}$ cells to respond for the rapid elimination of antigens, and this effect is regulated by inflammatory factors (Shetty et al., 2018). LSECs also express major histocompatibility complex class II molecules but are more inclined to promote the differentiation of naive $\mathrm{CD} 4^{+} \mathrm{T}$ cells into regulatory $\mathrm{T}$ cells rather than $\mathrm{T}$ helper cells (Knolle et al., 1999; Carambia et al., 2014; Shetty et al., 2018).

\section{THE PRO- AND ANTI-INFLAMMATORY DUAL EFFECTS OF LIVER SINUSOIDAL ENDOTHELIAL CELLS IN NONALCOHOLIC FATTY LIVER DISEASE}

The development of liver inflammation is a key step causing liver injury, regardless of etiologies (Shetty et al., 2018). In NAFLD, infiltrated leukocytes are recruited from the circulation, mainly bone marrow-derived macrophages (BMMs) and neutrophils, into liver parenchyma, and this leads to the formation of inflammatory foci, and thus accelerates the disease progression from simple steatosis to steatohepatitis (Rinella, 2015). In general, circulating leukocytes are first captured by activated endothelial cells and then migrate through the endothelium to the site of infection or injury (Shetty et al., 2018). The recruitment of leukocytes is an outcome of multi-step adhesion cascades involving various cytokines and receptors on the surface of leukocyte and LSEC (Tanaka et al., 1993; Adams et al., 1996; Wong et al., 1997; Campbell et al., 1998; Nourshargh and Alon, 2014; McEver, 2015; Muller, 2016). In most vascular beds, selectin receptors mediate the capture of circulating leukocytes and cause them to roll on the endothelial surface, which is a general initial step for leukocyte recruitment. However, in hepatic sinusoids, the "rolling" is not an essential step for leukocyte recruitment and thus the selectin may have a minimal function due to the narrow structure and low shear stress (Adams et al., 1996; Wong et al., 1997). Further, stimulated by chemokines, the integrins on the surface of the leukocytes are activated and then mediate a firm adhesion between leukocytes and endothelium. Finally, leukocytes migrate through the endothelium into the liver parenchyma mediated by complex receptor-ligand interactions (Muller, 2016). In most organs, recruitment of leukocytes mainly occurs in post-capillary venules, while in the liver, most leukocyte recruitment occurs in sinusoidal cavities (Shetty et al., 2018). Therefore, LSECs control the key path of inflammation and thus play a pivotal role in the occurrence and progression of liver inflammation (Figure 2).

\section{Pro-inflammatory Effects of Liver Sinusoidal Endothelial Cells Capillarization of Liver Sinusoidal Endothelial Cells Promotes Inflammation in Early Nonalcoholic Fatty Liver Disease}

LSECs undergo morphological changes in specific cases, such as viral infection, chronic liver diseases, and aging (Schaffner and Poper, 1963; Horn et al., 1987; Xu et al., 2003; Warren et al., 2007; Baiocchini et al., 2019; Hunt et al., 2019). Capillarization is the most common and prominent phenotypic change of LSECs, which is mainly manifested by the loss of fenestrae and the formation of a basement membrane on the abluminal surface, and thus it is also called dedifferentiation (Figure 3) (Maslak et al., 2015a). Capillarization of LSECs occurs in lipid-treated LSECs, animal NAFLD models, and patients with NAFLD (Akyol et al., 2005; Peng et al., 2014; Zhang et al., 2014; Miyao et al., 2015; Bravo et al., 2019; Zhang et al., 2019). Treatment with ox-LDL only or plus high glucose induced human LSEC injury and thus caused a reduction in porosity of LSECs (Zhang et al., 2014; Zhang et al., 2019). Shown with a scanning electron microscopy or marker of capillarization indicators such as CD31 and CD34, the capillarization of LSECs was observed at the early stage of NAFLD in animal models induced by diet, including high fat diet (HFD), choline-deficient L-amino acid-defined (CDAA) diet, and high fat glucose-fructose diet (HFGFD) (Table 1) (Peng et al., 2014; Miyao et al., 2015; Bravo et al., 2019). In patients with NAFLD, CD31 was significantly higher expressed in zone 3 (centrilobular area) (Akyol et al., 2005). Certainly, the 


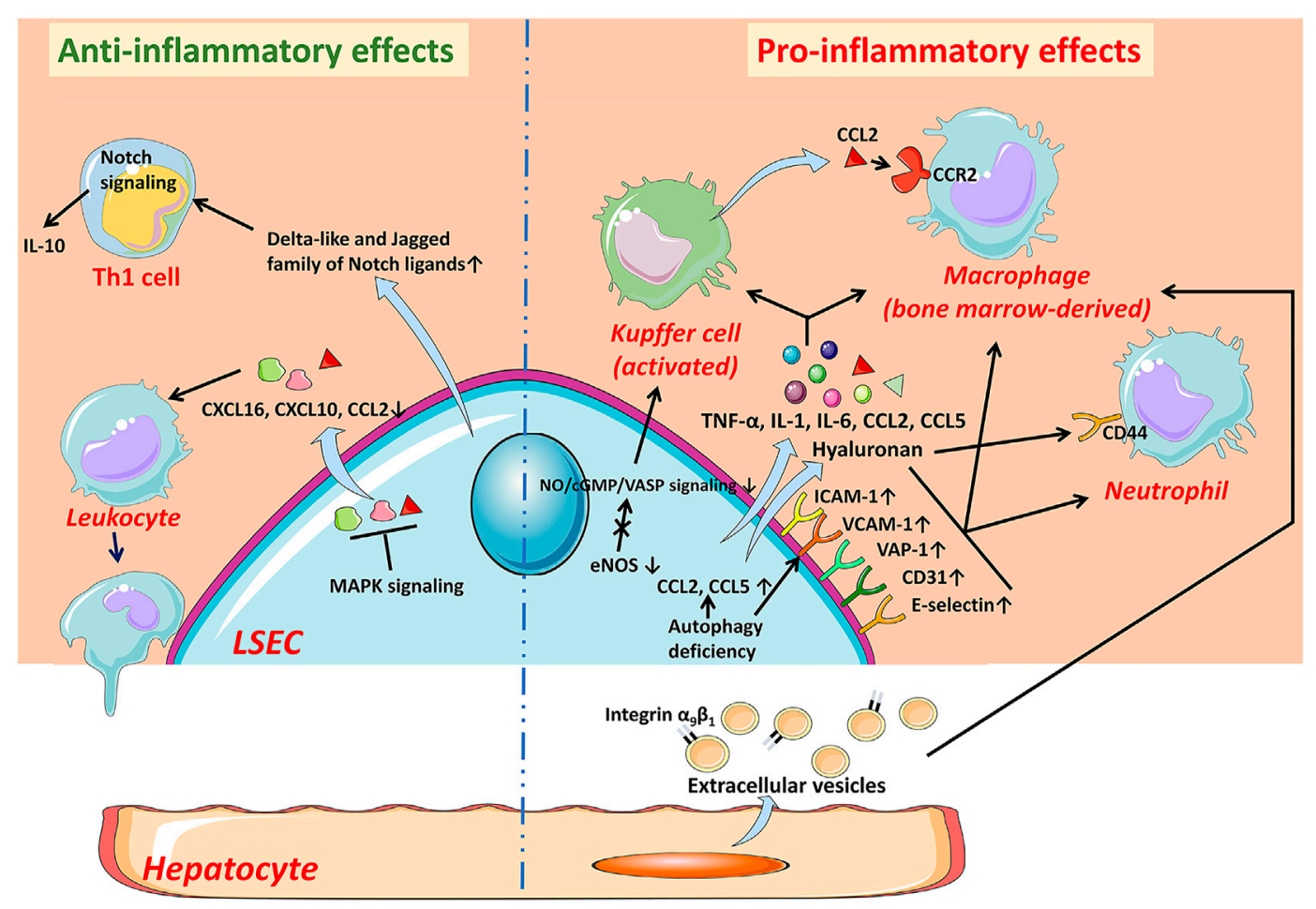

FIGURE 2 | The anti-inflammatory and pro-inflammatory effects of LSECs in NAFLD. In the early stage of NAFLD, LSECs develop an anti-inflammatory phenotype manifested by the decreased expression of chemokines CCL2, CXCL10, and CXCL16 through MAPK signaling-dependent manner. LSECs can also promote the secretion of IL-10 by Th1 cells via releasing Notch ligands to exert anti-inflammatory effects. While LSECs characterized as pro-inflammatory phenotype, increase expression of adhesion factors including VCAM-1, ICAM-1, E-selectin, CD31, and VAP-1, leading to increased recruitment of leukocytes. The deficiency of autophagy also leads to up-regulation of adhesion factors and chemokines. Pro-inflammatory mediators released by LSECs, such as TNF- $\alpha$, IL-1, and IL-6, also promote the progress of inflammation. The reduction of $\mathrm{NO}$ bioavailability contributes to the activation of KCs and the recruitment of bone marrow-derived macrophages. The hyaluronan densely coated on the surface of LSECs facilitates the recruitment of neutrophils by interacting with CD44. In addition, hepatocyte-derived EVs contribute to the recruitment of macrophages into the hepatic sinusoids. CCL C-C motif chemokine ligand, CCR C-C motif chemokine receptor, CXCL C-X-C motif chemokine ligand, eNOS endothelial nitric oxide synthase, ICAM-1 intercellular adhesion molecule-1, IL interleukin, LSEC liver sinusoidal endothelial cell, NO Nitric oxide, TNF- $\alpha$ tumor necrosis factor- $\alpha$, VAP-1 vascular adhesion protein-1, VCAM-1 vascular cell adhesion molecule-1.

capillarization of LSECs occurs earlier than the onset of general liver inflammation. Miyao and colleagues found that the reduced porosity of LSECs was earlier than inflammation and activation of KCs and HSCs, which occurred in C57BL/6 mice after 1 week of CDAA diet (Miyao et al., 2015). Straub and colleagues found that CD45/CD68-positive inflammatory cells did not accumulate in the liver until the porosity of LSECs decreased by low-level arsenic, indicating that inflammation may be the consequence of LSECs capillarization (Straub et al., 2007). However, subjected to several variable factors, including the heterogeneity of animal models and LSECs isolated in vitro, the difference of detection methods, indicators, and techniques, whether the capillarization of LSECs occurs throughout NAFLD is still controversial.

Intracellular protein expression abnormality or signaling pathway disturbance contributes to capillarization of LSEC (Figure 3). Hedgehog signaling was activated and thus regulated phenotypic changes to form LSEC capillarization, while inhibitors of Hedgehog pathway partially reversed the capillarized LSECs to a healthy differentiated phenotype and completely prevented LSECs from becoming capillarized both in vitro and in vivo (Xie et al., 2013). Capillarization of LSEC was also inhibited by liver $\mathrm{X}$ receptor (LXR) $\alpha$ via suppressing Hedgehog signaling (Xing et al., 2016). Although LXR agonists have shown therapeutic potential in anti-inflammatory and antifibrotic aspects, whether these beneficial effects are mainly through alleviating the capillarization of LSECs still needs further exploration (Xing et al., 2016). Lectin-like oxidized low-density lipoprotein receptor-1 (LOX-1) mediates capillarization through reactive oxygen species/nuclear factor$\kappa \mathrm{B}$ signaling pathway in LSECs treated with ox-LDL (Zhang et al., 2014). LOX-1 was up-regulated by many pro-inflammatory cytokines, including transforming growth factor $-\beta$, IL-1 $\alpha$, IL$1 \beta$, IL-6, and tumor necrosis factor- $\alpha$ (TNF- $\alpha$ ), indicating that capillarization and inflammatory response may be mutually reinforced in NAFLD (Navarra et al., 2010; Ozturk et al., 2015). Recently, delta-like ligand 4 (DLL4), a ligand of the Notch signaling pathway, was found to mediate the capillarization of LSECs and the vicious circle between fibrosis and pathological sinusoidal remodeling (Chen et al., 2019).

Paracrine signaling is important for maintaining the differentiated phenotype of LSEC (Figure 3). Bone morphogenetic protein 9 (BMP9), as a paracrine factor 


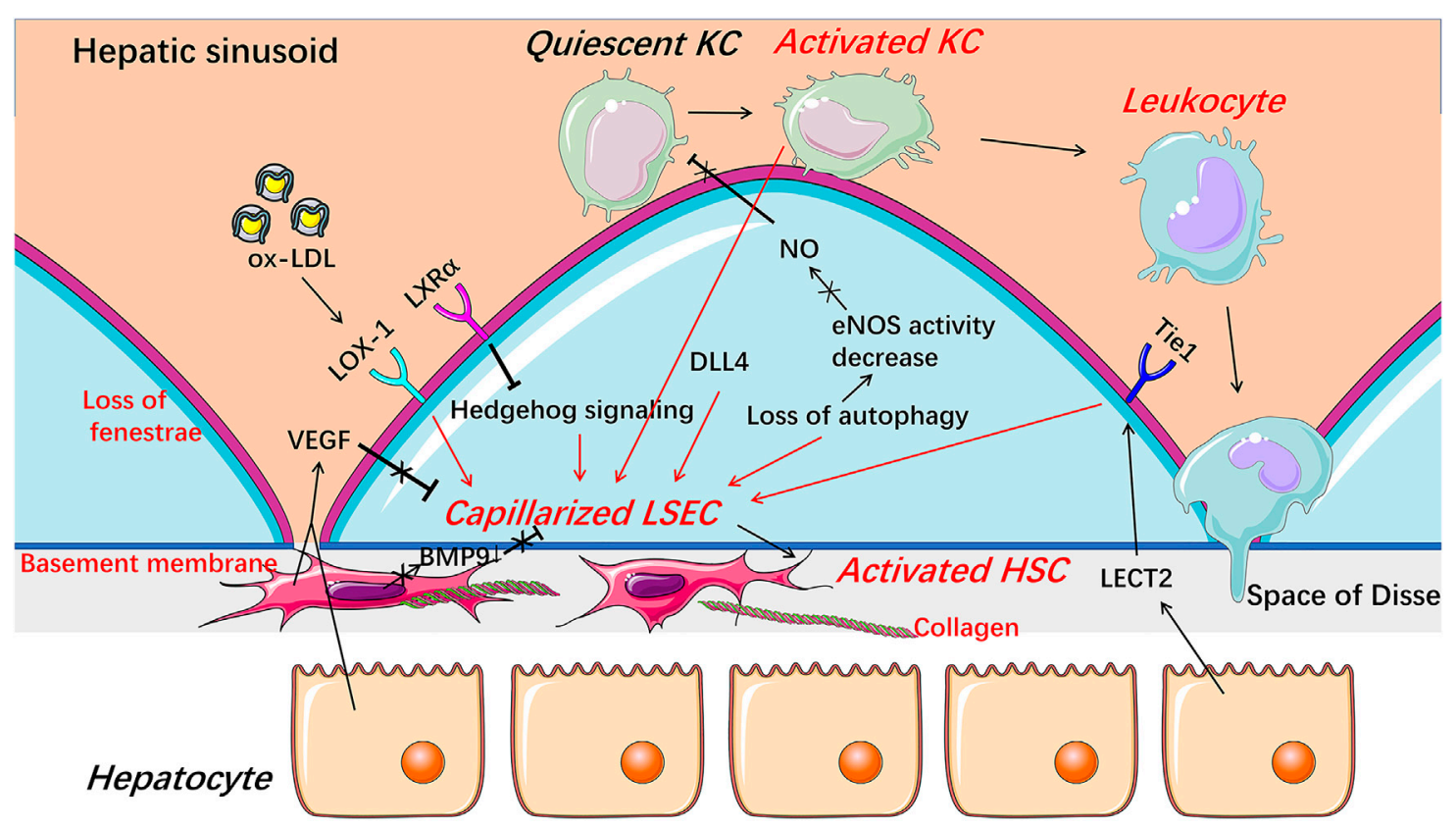

FIGURE 3 | Capillarization and endothelial dysfunction of LSECs under pathological condition. When injured, LSECs undergo capillarization represented by the loss of fenestrae and the formation of basement membrane which are involved in Hedgehog signaling, autophagy, HSCs-derived BMP9, LSECs-derived DLL4, and receptors including LOX-1, LXRa, and Tie1. The reduction of NO bioavailability is an important indicator of endothelial dysfunction and involved in the progress of the capillarization of LSECs. Capillarized and dysfunctional LSECs promote the activation of HSCs and KCs and thus promote liver fibrosis and inflammation. BMP9 Bone morphogenetic protein 9, DLL4 Delta-like ligand 4, HSC hepatic stellate cell, KC Kupffer cell, LECT2 leukocyte cell-derived chemotaxin 2, LSEC liver sinusoidal endothelial cell, $L X R \alpha$ liver $X$ receptor a, LOX-1 lectin-like oxidized low-density lipoprotein receptor-1, NO Nitric oxide, ox-LDL oxidized low-density lipoproteins, VEGF vascular endothelial growth factor.

TABLE 1 | Summary of capillarization and endothelial dysfunction of LSECs in NAFLD animal models.

\begin{tabular}{|c|c|c|c|c|c|c|c|c|c|c|}
\hline Model & Species & Capillarization & Stage & $\begin{array}{l}\text { Endothelial } \\
\text { dysfunction }\end{array}$ & Stage & $\begin{array}{l}\text { Capillarization } \\
\text { Indicator(s) }\end{array}$ & SEM & AFM & Year & Ref \\
\hline HFD & $\begin{array}{l}\text { C57BL/6 } \\
\text { mice }\end{array}$ & Not mentioned & $\mathrm{N} / \mathrm{A}$ & Yes & $\begin{array}{l}\text { Early (4 } \\
\text { weeks) }\end{array}$ & $\mathrm{N} / \mathrm{A}$ & No & No & 2011 & Tateya et al. (2011) \\
\hline CafD & $\begin{array}{l}\text { Wistar kyoto } \\
\text { rats }\end{array}$ & No & Early (1 month) & Yes & $\begin{array}{l}\text { Early (1 } \\
\text { month) }\end{array}$ & $\begin{array}{l}\text { SE-1, CD31, } \\
\text { CD34 }\end{array}$ & No & No & 2012 & $\begin{array}{l}\text { Pasarin et al. } \\
(2012)\end{array}$ \\
\hline HFD & SD rat & Yes & $\begin{array}{l}\text { Probably early } \\
\text { (43rd day) }\end{array}$ & $\begin{array}{l}\text { Not } \\
\text { mentioned }\end{array}$ & N/A & No & Yes & No & 2014 & Peng et al. (2014) \\
\hline CDAA & $\begin{array}{l}\text { C57BL/6 } \\
\text { mice }\end{array}$ & Yes & Early (1 week) & $\begin{array}{l}\text { Not } \\
\text { mentioned }\end{array}$ & N/A & CD31, CD34 & Yes & No & 2015 & Miyao et al. (2015) \\
\hline HFD & $\begin{array}{l}\text { C57BL/6 } \\
\text { mice }\end{array}$ & Yes & Late (22 weeks) & $\begin{array}{l}\text { Not } \\
\text { mentioned }\end{array}$ & N/A & No & Yes & No & 2015 & Miyao et al. (2015) \\
\hline MCD & $\begin{array}{l}\text { C57BL/6 } \\
\text { mice }\end{array}$ & Not mentioned & $\mathrm{N} / \mathrm{A}$ & Yes & $\begin{array}{l}\text { Early (4 } \\
\text { weeks) }\end{array}$ & $\mathrm{N} / \mathrm{A}$ & No & No & 2015 & $\begin{array}{l}\text { Pourhoseini et al. } \\
\text { (2015) }\end{array}$ \\
\hline HFGFD & SD OFA rats & Yes & Early (10 weeks) & Yes & $\begin{array}{l}\text { Early (10 } \\
\text { weeks) }\end{array}$ & CD31 & No & No & 2019 & Bravo et al. (2019) \\
\hline HFD & $\begin{array}{l}\text { C57BL/6 } \\
\text { mice }\end{array}$ & No & $\begin{array}{l}\text { Early ( } 2 \text { weeks) and late } \\
\text { ( } 20 \text { weeks) }\end{array}$ & $\begin{array}{l}\text { Not } \\
\text { mentioned }\end{array}$ & $\mathrm{N} / \mathrm{A}$ & No & Yes & Yes & 2019 & Kus et al. (2019) \\
\hline
\end{tabular}

AFM, atomic force microscopy; CafD, cafeteria diet; CDAA, choline-deficient I-amino acid-defined; HFD, high fat diet; HFGFD, high fat glucose-fructose diet; MCD, methionine and choline deficient; N/A, not applicable; SEM, scanning electron microscopy

derived from HSCs, maintains the fenestrated phenotype of LSECs, contributing to liver homeostasis (Desroches-Castan et al., 2019). In patients with NASH, hepatic mRNA expression of BMP9 was decreased (John et al., 2019). Knocking out mouse BMP9 gene induced capillarization of
LSECs in vivo, while treatment with an addition of BMP9 maintained the fenestration of primary cultured LSECs in vitro, and an absence of LSEC fenestrae occurred followed by liver inflammation and fibrosis in BMP9 gene knock-out mice (Miyao et al., 2015; Desroches-Castan et al., 2019). Leukocyte 
cell-derived chemotaxin 2 (LECT2), a functional ligand of Tie1 expressed by hepatocytes and endothelial cells, promotes the capillarization of LSECs in the liver fibrosis rodent model (Xu et al., 2019). Vascular endothelial growth factor (VEGF), as a paracrine signal produced by hepatocytes and HSCs, maintains the differentiated phenotype of LSECs (DeLeve et al., 2004). When co-cultured with HSCs or hepatocytes in vitro, the expression of CD31 on the surface of LSECs was decreased, while anti-VEGF antibody reversed the decrease (DeLeve et al., 2004). Fortuitously, NO synthase inhibitor blocked the stabilizing effect of hepatocytes or HSCs on LSECs phenotype in the co-cultured system, suggesting that NO may be also necessary for maintaining the differentiated phenotype of LSECs and that the decreased NO bioavailability may promote the capillarization of LSECs, which may be associated with endothelial dysfunction of LSECs (DeLeve et al., 2004; Flammer et al., 2012; Hammoutene and Rautou, 2019).

Capillarization of LSECs promotes the development of steatosis in NAFLD. On the one hand, the capillarization of LSECs prevents the release of very-low-density lipoprotein (VLDL) from hepatocytes into the sinusoidal cavity, resulting in the retention of lipids including cholesterol and triglycerides in the liver (Hammoutene and Rautou, 2019). On the other hand, the capillarization of LSECs prevents the entry of chylomicron remnants into hepatocytes, stimulating the de novo lipogenesis of liver lipids and eventually inducing steatosis in a compensatory way since the chylomicron remnants are required for the synthesis of VLDL by hepatocytes (Herrnberger et al., 2014; Tanaka and Iwakiri, 2016). However, studies showed that excessive lipid exposure, such as ox-LDL, leads to a decrease in the fenestrae diameter and porosity of LSECs (Zhang et al., 2014). Furthermore, Cogger and colleagues demonstrated that the porosity and fenestrae frequency of LSECs are negatively correlated with dietary fat intake and circulating FFA in vivo (Cogger et al., 2016). These data suggested that the early formation of steatosis will, in turn, promotes the capillarization of LSECs, which further facilitates the development of steatosis to inflammation in patients with NAFLD.

\section{Dysfunction of Liver Sinusoidal Endothelial Cells Promotes Inflammation in Nonalcoholic Fatty Liver Disease}

Endothelial dysfunction of LSECs is a pathological condition mainly characterized by an abnormal imbalance between vascular endothelium-derived relaxing factors and contracting factors, resulting in an inability to expand blood vessels when blood flow increase (Flammer et al., 2012). Much evidence suggest that endothelial dysfunction of LSECs promotes inflammation in NAFLD.

First, endothelial dysfunction of LSECs occurs earlier than liver inflammation in NAFLD (Table 1). Arterial endothelial dysfunction of LSECs was confirmed in patients with NAFLD, and the occurrence of sinusoidal endothelial dysfunction of LSECs was earlier than inflammation in various early stage NAFLD rodent models induced by diet, including cafeteria diet (CafD), HFD, and methionine-choline-deficient (MCD) diet, showing with a marked increased vascular resistance, or increased portal perfusion pressure and reduced endotheliumdependent vasodilatory response (Villanova et al., 2005; Tateya et al., 2011; Francque et al., 2012; Pasarin et al., 2012; Pourhoseini et al., 2015; Gonzalez-Paredes et al., 2016; Bravo et al., 2019). The dysfunction mechanism may be related to a decreased phosphorylation of Akt-dependent endothelial nitric oxide synthase (eNOS) and NO synthase activity, which reduces liver eNOS activity and NO content, respectively, and the consequence was occurred earlier than general liver inflammation in the rodent NAFLD model (Tateya et al., 2011; Pasarin et al., 2012; Gonzalez-Paredes et al., 2016; Bravo et al., 2019).

Second, endothelial dysfunction of LSECs promotes activation of KCs to facilitate the occurrence of inflammation in NAFLD (Lanthier, 2015). KCs are resident macrophages in liver sinusoids that are in close contact with LSECs and can be activated by various factors, including pathogen-associated molecular patterns such as lipopolysaccharide (LPS), damage-associated molecular patterns released by damaged hepatocytes, and lipids such as free fatty acids (FFAs), ceramides, and oxidized lipoproteins (Leroux et al., 2012; Sawada et al., 2014; Zannetti et al., 2016). In NASH patients, an expansion of KCs is an early phenomenon, earlier than the recruitment of other immune cells (Gadd et al., 2014). As a hepatic immune gatekeeper, LSEC maintains KCs quiescence under physiological conditions through NO-dependent pathways (Tateya et al., 2011). However, under pathological conditions, reduced endothelial NO bioavailability promotes the activation of KCs to cause liver inflammation manifested by activation of nuclear factor$\kappa \mathrm{B}$ and upregulation of pro-inflammatory factors TNF- $\alpha$ and IL- 6 in mice (Tateya et al., 2011). The activated KCs promote the capillarization of LSECs and lead to subsequent leukocyte recruitment (Arii and Imamura, 2000; Ford et al., 2015; Shetty et al., 2018). Therefore, the dysfunction of LSECs promotes activation of $\mathrm{KCs}$, which in turn contributes to the morphological changes and activation of LSECs, and this interaction leads to exacerbation of liver inflammatory response in the early stage of NAFLD. Certainly, ameliorating endothelial dysfunction of LSECs can improve liver inflammation in animal models by manipulating the NO signal pathway using sildenafil or simvastatin (Tateya et al., 2011; Wang et al., 2013; Ahsan et al., 2020).

Third, under pathological conditions, autophagy of LSECs is often abnormal. Autophagy, a major intracellular recycling system, maintains cellular homeostasis under basal conditions and acts as a survival mechanism under stress conditions (Hammoutene et al., 2020). Defect autophagy with smaller autophagic vacuoles in LSECs occurs in patients with NASH. The endothelial cell-specific loss of autophagy leads to a significant decrease in porosity and the number of fenestrae of LSECs in mice after mild acute liver injury and an increase in the expression of pro-inflammatory chemokines C-C motif chemokine ligand (CCL) 2, CCL5, and vascular cell adhesion molecule (VCAM-1), and thus promotes inflammation in mice fed with HFD (Ruart et al., 2019; Hammoutene et al., 2020). Interestingly, in different cell types, autophagy may play 
differential roles in chronic liver diseases (Choi et al., 2013; Allaire et al., 2019). For example, in hepatocytes, autophagy helps to protect cells from fat accumulation and prevents liver damage by removing altered mitochondria and reducing intracellular stresses. In macrophages, it has anti-inflammatory effects and thus prevents liver inflammation and fibrosis. While in activated HSCs and LSECs, autophagy promotes liver disease progression (Berg et al., 2006; Hernandez-Gea et al., 2012; Lodder et al., 2015; Madrigal-Matute and Cuervo, 2016; Gual et al., 2017; GraciaSancho and Guixe-Muntet, 2018; Hammoutene et al., 2020). Therefore, the specific mechanism of autophagy abnormality in LSECs leading to capillarization and inflammation still needs more exploration.

The dysfunction of LSECs promotes steatosis by increasing intrahepatic vascular resistance, which is related to the formation of steatosis (Tateya et al., 2011; Francque et al., 2012; Gonzalez-Paredes et al., 2016; Baffy, 2018). NO plays an important role in regulating liver lipid content and fatty acid synthesis (Roediger et al., 2004; Schild et al., 2008; Tateya et al., 2011; Doulias et al., 2013). In NO-deficient eNOS knockout mice, large amounts of lipid droplets and elevated liver triglyceride levels were observed, while treatments with increasing the availability of NO improved not only liver inflammation but also liver steatosis (Schild et al., 2008; Tateya et al., 2011). However, steatosis, in turn, promotes the dysfunction of LSECs. The mechanism may be that excess lipids of steatosis decreased eNOS expression and thus reduced the bioavailability of NO (Pasarin et al., 2011; Pasarin et al., 2012; Pasarin et al., 2017). Besides, insulin resistance caused by steatosis can damage the vasodilation function of LSECs through the decrease of eNOS and the increase of inducible nitric oxide synthase (iNOS) (Chauhan et al., 2003; Pasarin et al., 2017).

\section{Liver Sinusoidal Endothelial Cells Promote Inflammation by the Recruitment of BMMs and Neutrophils in Nonalcoholic Steatohepatitis}

Recruited BMMs are an important component of chronic liver inflammation in NASH, where LSECs play a crucial role in the recruitment of BMMs (Koyama and Brenner, 2017). The dysfunction of LSECs facilitates the recruitment of macrophages in NASH through promoting KCs activation to release CCL2, which is the ligand of $\mathrm{C}-\mathrm{C}$ motif chemokine receptor (CCR) two mainly expressed on monocytes and macrophages and thus is critical for the recruitment of macrophages (Tateya et al., 2011; Miura et al., 2012). Furthermore, LSECs also promote the recruitment of leukocytes, including but not limited to BMMs, directly by increasing the expression of adhesion molecules including intercellular adhesion molecule-1 (ICAM-1), VCAM-1, vascular adhesion protein-1 (VAP-1), E-selectin, and CD31, which are essential for the interaction between LSECs and leukocytes to recruit leukocytes (Edwards et al., 2005; Weston et al., 2015; Miyachi et al., 2017; Hammoutene and Rautou, 2019; Kus et al., 2019). In addition to this pro-inflammatory phenotype, LSECs produce pro-inflammatory mediators, including IL-1, IL6 , TNF- $\alpha$, and CCL2, to promote activation of inflammatory cells and the recruitment, adhesion, and migration of BMMs and neutrophils in NASH (Miyachi et al., 2017; Roh and Seki, 2018; Hammoutene and Rautou, 2019).

Recent research shows that the recruitment of BMMs by LSECs is partly influenced by extracellular vesicle (EV) derived from hepatocytes. EV is a general term for membrane vesicles released by cells, it plays an important role in liver physiology and pathology, which has been reviewed well elsewhere (Hirsova et al., 2016b; Eguchi and Feldstein, 2018). In NASH, EVs released by hepatocytes under pressure stimulation contribute to the occurrence of liver inflammation by inducing proinflammatory cytokines expression and activating macrophage chemotaxis and thus promoting macrophages recruitment (Hirsova et al., 2016a; Garcia-Martinez et al., 2016; Ibrahim et al., 2016; Kakazu et al., 2016). Recently, Guo and colleagues found that integrin $\alpha_{9} \beta_{1}$-enriched EVs released by lysophosphatidylcholine-treated hepatocytes interact with monocytes in a topography and assist monocytes to adhere to LSECs in vivo and in vitro (Guo et al., 2019). However, the influence of other cell-derived EVs on LSECs and the effect of LSECs-derived EVs on macrophage recruitment in NASH require more researches.

Besides BMMs, neutrophil infiltration is also commonly observed in patients with NAFLD, and its severity is associated with the development of the disease (Nati et al., 2016; Cai et al., 2019). In the inflammatory state, neutrophils upregulate the expression of adhesion molecules and activate endothelial cells and KCs, which induce the further recruitment of other leukocytes including BMMs, where neutrophils are excessively activated and release proteases such as myeloperoxidase causing liver damage, and thus aggravate the ongoing inflammatory state (Arrese et al., 2016; Nati et al., 2016; Cai et al., 2019). In the inflamed hepatic sinusoids, highly coated hyaluronan on the luminal surface of LSECs interacts with CD44 on the surface of neutrophils and thus mediates the recruitment of neutrophils (McDonald et al., 2008). Unlike other vascular endothelial cells, LSEC anchoring hyaluronan does not depend on the endothelial CD44. Instead, LSECs capture the circulating hyaluronan through a variety of SRs such as stabilin- 2 on the cell surface and then present it to the passing neutrophils before promoting the endocytosis of hyaluronan ultimately (McDonald and Kubes, 2015). Therefore, it is necessary to study the role of SRs on LSECs in LSECs-mediated leukocyte recruitment.

\section{Anti-inflammatory Effects of Liver Sinusoidal Endothelial Cells in Nonalcoholic Fatty Liver Disease}

Liver Sinusoidal Endothelial Cells Prevent Formation of Inflammation by Inhibiting Leukocyte Recruitment in the Early Stage of Nonalcoholic fatty liver disease In the early stage of NAFLD models, evidence suggest that LSECs suppress leukocyte recruitment into hepatic sinusoids (McMahan et al., 2016). An anti-inflammatory phenotype of LSECs, characterized by decreased expressions of CCL2, C-X-C motif chemokine ligand (CXCL) 10, and CXCL16, was produced in both murine and human LSECs after a short time exposure to 
TABLE 2 | Inflammation-targeted pharmacologic agents that have completed or are undergoing clinical trials for NASH.

\begin{tabular}{|c|c|c|c|c|c|c|}
\hline $\begin{array}{l}\text { Mechanism of } \\
\text { action }\end{array}$ & $\begin{array}{l}\text { Agent } \\
\text { name }\end{array}$ & Company(s) & $\begin{array}{c}\text { Trial } \\
\text { phase }\end{array}$ & Primary endpoint(s) & $\begin{array}{c}\text { Primary } \\
\text { completion }\end{array}$ & $\begin{array}{l}\text { Clinical } \\
\text { trial ID }\end{array}$ \\
\hline CCR2/5 inhibitor & Cenicriviroc & Allergan & 3 & $\begin{array}{l}\text { 1. Improvement in fibrosis without worsening } \\
\text { steatohepatitis; } 2 \text {. Long-term clinical outcomes }\end{array}$ & Oct 2021 & NCT03028740 \\
\hline \multirow[t]{2}{*}{ ASK1 inhibitor } & Selonsertib & Gilead & 3 & $\begin{array}{l}\text { 1. Improvement in fibrosis without worsening of } \\
\mathrm{NASH} ; 2 \text {. Event-free survival }\end{array}$ & Jun 2019 & NCT03053050 \\
\hline & & & 3 & $\begin{array}{l}\text { 1. Improvement in fibrosis without worsening of } \\
\mathrm{NASH} ; 2 \text {. Event-free survival }\end{array}$ & May 2019 & NCT03053063 \\
\hline \multirow[t]{2}{*}{ Pan-caspase inhibitor } & Emricasan & $\begin{array}{l}\text { Novartis/Conatus } \\
\text { pharmaceuticals }\end{array}$ & 2 & $\begin{array}{l}\text { Improvement in fibrosis without worsening of } \\
\text { steatohepatitis }\end{array}$ & Jan 2019 & NCT02686762 \\
\hline & & & 2 & $\begin{array}{l}\text { Improvement in event-free survival based on a } \\
\text { composite clinical endpoint }\end{array}$ & Aug 2019 & NCT03205345 \\
\hline \multirow[t]{2}{*}{ TLR-4 antagonist } & JKB-121 & TaiwanJ & 2 & Change from baseline in hepatic fat & Sept 2017 & NCT02442687 \\
\hline & $\mathrm{JKB}-122$ & TaiwanJ & 2 & $\begin{array}{l}\text { 1. Reduction in NAS without worsening of fibrosis; } \\
\text { 2. Improvement in fibrosis without worsening } \\
\text { of NAS }\end{array}$ & Jun 2023 & NCT04255069 \\
\hline $\begin{array}{l}\text { Mineralocorticoid } \\
\text { receptor antagonist }\end{array}$ & MT-3995 & $\begin{array}{l}\text { Mitsubishi tanabe } \\
\text { pharma }\end{array}$ & 2 & Percent change from baseline in ALT & Mar 2018 & NCT02923154 \\
\hline \multirow[t]{2}{*}{ VAP-1 inhibitor } & $\mathrm{Bl}-1467335$ & Boehringer ingelheim & 2 & Target enzyme activity relative to baseline in percent & Jun 2019 & NCT03166735 \\
\hline & TERN-201 & Terns pharmaceuticals & 1 & Safety and tolerability & & \\
\hline
\end{tabular}

ALT, alanine aminotransferase; ASK1, apoptosis signal-regulating kinase 1; CCR2/5, C-C motif chemokine receptor 2/5; NAS, non-alcoholic fatty liver disease activity score; NASH, nonalcoholic steatohepatitis; TLR-4, toll-like receptor-4; VAP-1, vascular adhesion protein-1.

FFA, and thus reduced the recruitment of pro-inflammatory monocytes. Primary LSECs isolated from obese mice also showed the consequence (McMahan et al., 2016). Further study demonstrated the anti-inflammatory ability produced by LSECs under FFA induction depends on the MAPK signaling pathway, which is important for the survival of LSECs in the case of lipid induction, and it also may be involved with signal transducer and activator of transcription 3 (STAT3) for its expression in LSECs alleviated mice liver inflammation induced by alcohol (Miller et al., 2010; Hang et al., 2012; McMahan et al., 2016).

\section{Liver Sinusoidal Endothelial Cells Regulate Lymphocytes to Exert Anti-inflammatory Effects}

LSECs regulate a behavior of lymphocytes under both physiological and pathological conditions (Poisson et al., 2017). Under physiological conditions, LSECs maintain the intrahepatic tolerance environment through inducing tolerant $\mathrm{CD}^{+} \mathrm{T}$ cell and immunosuppressed regulatory $\mathrm{T}$ cells (Limmer et al., 2000; Carambia et al., 2014). While under inflammatory conditions, LSECs express high levels of Delta-like and Jagged family of Notch ligands and induce the expression of Notch target genes in Th1 cells, by which increases the expression of inflammatory cytokine IL-10 in Th1 cells to exert an antiinflammatory effect (Neumann et al., 2015).

\section{THERAPEUTIC PERSPECTIVES}

Currently, no specific drug has been approved for clinical use to treat patients with NASH. There are many promising candidates in the drug development pipeline, and some have shown very useful for improving NASH by controlling inflammation in clinical trials (Table 2), such as dual CCR2/5 inhibitor, apoptosis signal-regulating kinase 1 (ASK1) inhibitor, and caspase inhibitor (Romero et al., 2020). Unfortunately, the latest clinic outcomes of selonsertib (an ASK1 inhibitor) and emricasan (a pan-caspase inhibitor) are not satisfied (Loomba et al., 2018; Harrison et al., 2020; Ratziu et al., 2020; Romero et al., 2020). Thus, it is still urgent and important to find new antiinflammatory targets in NASH. Most encouragingly, the essential role of LSECs in liver inflammation provides new insights into the development of treatment strategies for NAFLD/NASH.

\section{Targeting Adhesion-Related Molecules to Alleviate Inflammation in Nonalcoholic Steatohepatitis}

Adhesion molecules are abnormally expressed on LSECs in response to liver injury and regulate inflammation via corresponding ligands. Therefore, adhesion molecules and their ligands related to LSECs are provided with multiple potential targets to control inflammation in NASH. The proinflammatory phenotype of LSECs showed increased expression of adhesion molecules including VAP-1, VCAM-1, CD31, ICAM-1, and E-selectin (Hammoutene and Rautou, 2019; Kus et al., 2019). Blocking these molecules or their ligands is efficacious to control inflammation in various NASH models (Edwards et al., 2005; Weston et al., 2015; Miyachi et al., 2017; Hammoutene and Rautou, 2019). In particular, VAP-1 inhibitors have entered clinical trials. However, unfortunately, a VAP-1 inhibitor BI 1467335 was recently discontinued for NASH indications due to its interaction with other drugs, although the results of the latest clinical studies (phase IIa, NCT03166735) did not indicate a direct failure of BI 1467335 in terms of efficacy and tolerance (Boehringer ingelheim, 2019). Another potent VAP-1 inhibitor, TERN-201, is still undergoing clinical trials in China for the treatment of NASH (Terns 
Pharmaceuticals., 2019). Blocking the interaction between the adhesion molecule CD44 and its ligand hyaluronan using an antiCD44 antibody also exhibits a potential inflammation-controlling effect both in LPS-induced or diet-induced mouse models, but further research is still needed in NASH (McDonald et al., 2008; Kodama et al., 2015; McDonald and Kubes, 2015).

Chemokines are chemo-attractants for leukocyte trafficking, growth, and activation in injured and inflammatory tissues (Roh and Seki, 2018). They are also abnormally expressed and secreted by LSECs under pathological conditions. The anti-inflammatory phenotype of LSECs showed decreased expression of chemokines including CXCL10, CXCL16, and CCL2 (McMahan et al., 2016). Hopefully, the dual CCR2/5 inhibitor cenicriviroc was well tolerated in NASH patients and is currently undergoing a phase III clinical trial (NCT03028740) (Ratziu et al., 2020).

\section{Targeting Nitric Oxide Signaling to Improve Nonalcoholic fatty liver disease}

LSECs are the major producers of NO in the liver (Shah et al., 1997). The balance of NO is critical in maintaining the morphology and endothelial function of LSECs to keep the quiescence of HSCs and KCs, it also fundamentally participates in the regulation of liver lipid and glucose homeostasis (Maslak et al., 2015a). Therefore, targeting NOrelated signaling is an attractive therapeutic strategy to improve liver inflammation and alleviate liver damage. Some efforts to improve the bioavailability of NO in NAFLD have been made. V-PYRRO/NO, a stable hepato-selective NO-releasing prodrug, improved liver steatosis and postprandial glucose tolerance in NAFLD mice fed HFD (Maslak et al., 2015b). Praliciguat, a soluble guanylate cyclase stimulator, effectively reduced inflammation, fibrosis, and steatosis by enhancing NO signaling in preclinical NASH models (Hall et al., 2019). Besides, improvement of the NO/cGMP signaling pathway by using phosphodiesterase-5 inhibitor sildenafil or simvastatin prevented liver inflammation in NAFLD rodents fed HFD (Tateya et al., 2011; Wang et al., 2013; Ahsan et al., 2020).

\section{Targeting Angiogenesis to Improve Nonalcoholic fatty liver disease}

Hepatic angiogenesis, including the capillarization of LSECs, is an important event in the progression of NAFLD, especially in the formation of hepatic fibrosis (Coulon et al., 2011; Coulon et al., 2012; Coulon et al., 2013; Iwakiri et al., 2014). New blood vessels are produced in the liver of NASH patients, but not in individuals with simple steatosis or healthy liver (Kitade et al., 2008; Kitade et al., 2009; Lefere et al., 2019). In the serum of patients with $\mathrm{NASH}$, the level of VEGF, a major pro-angiogenesis regulator, was increased significantly (Yoshiji et al., 2006; Coulon et al., 2011; Tamaki et al., 2013; Lefere et al., 2019). Evidence of abnormal angiogenesis was also found in animal models of NASH (Coulon et al., 2013).

A variety of anti-angiogenic therapies have shown antiinflammatory effects in NASH animal models. Coulon and colleagues used specific antibodies to block vascular endothelial growth factor receptor 2 (VEGFR2) and found that liver inflammation and liver vasculature were significantly improved in the MCD-induced mouse NASH model, both in a preventive and therapeutic setting (Coulon et al., 2013). Studies have shown that serum level of angiopoietin-2, a key factor involved in regulating angiogenesis, is elevated in patients with NASH (Lefere et al., 2019). Inhibiting the interaction between angiopoietin-2 and its receptor Tie2 by using peptibody L1-10 effectively improved liver inflammation and damage in the NASH model induced by MCD (Lefere et al., 2019). It is worth noting that the therapeutic effect of L1-10, at least in part, is mediated by LSECs as evidenced by the downregulation of VCAM-1, ICAM-1, and CCL2 expression in liver endothelial cells isolated from the liver of NASH mouse (Lefere et al., 2019). Besides, LECT2, a functional ligand of endothelial cell-specific receptor Tie1, was recently found to promote liver fibrosis by inhibiting portal angiogenesis and promoting capillarization of liver sinusoids in various liver fibrosis models, providing a novel possible target for LSECs-mediated liver fibrosis (Xu et al., 2019). Therefore, studies on angiogenesis in the liver including capillarization of LSECs may provide new targets for NASH treatment.

\section{Targeting Pro-inflammatory EVs Specifically to Improve Inflammation}

Hepatocyte-derived EVs exert a regulatory ability in the recruitment of leukocytes to hepatic sinusoids. Therefore, blocking the production pathway of pro-inflammatory EVs or targeting pro-inflammatory cargos carried by EVs may improve liver inflammation in NASH, though the research in this area has only just begun (Hirsova et al., 2016a; Garcia-Martinez et al., 2016; Ibrahim et al., 2016; Kakazu et al., 2016; Guo et al., 2019). Using fasudil, an inhibitor of Rho-associated coiled coilcontaining protein kinase one that is required for membrane blebbing, to reduce the serum levels of hepatocytes-derived EVs, or using anti-integrin $\alpha_{9} \beta_{1}$ antibody alleviated liver damage, inflammation, and fibrosis in diet-induced NASH model (Hirsova et al., 2016a; Guo et al., 2019). However, EVs are widely involved in human physiology, and their cargos play different roles in different environments. Therefore, how to achieve cell- or tissue-specific targeting of EVs will be the focus of future research.

\section{Promoting Anti-inflammatory Behavior of Liver Sinusoidal Endothelial Cells to Improve Inflammation}

As the recruiter of BMMs and neutrophils, LSECs also have compensatory anti-inflammatory behaviors. On the one hand, LSECs can resist the recruitment of leukocytes through the production of anti-inflammatory phenotype, which is mainly manifested as a decrease in the expression of chemokines (McMahan et al., 2016). Therefore, increasing the ratio of the anti-inflammatory phenotype to the pro-inflammatory phenotype of LSECs may be an effective strategy to improve inflammation. However, the mechanism still needs to be further 


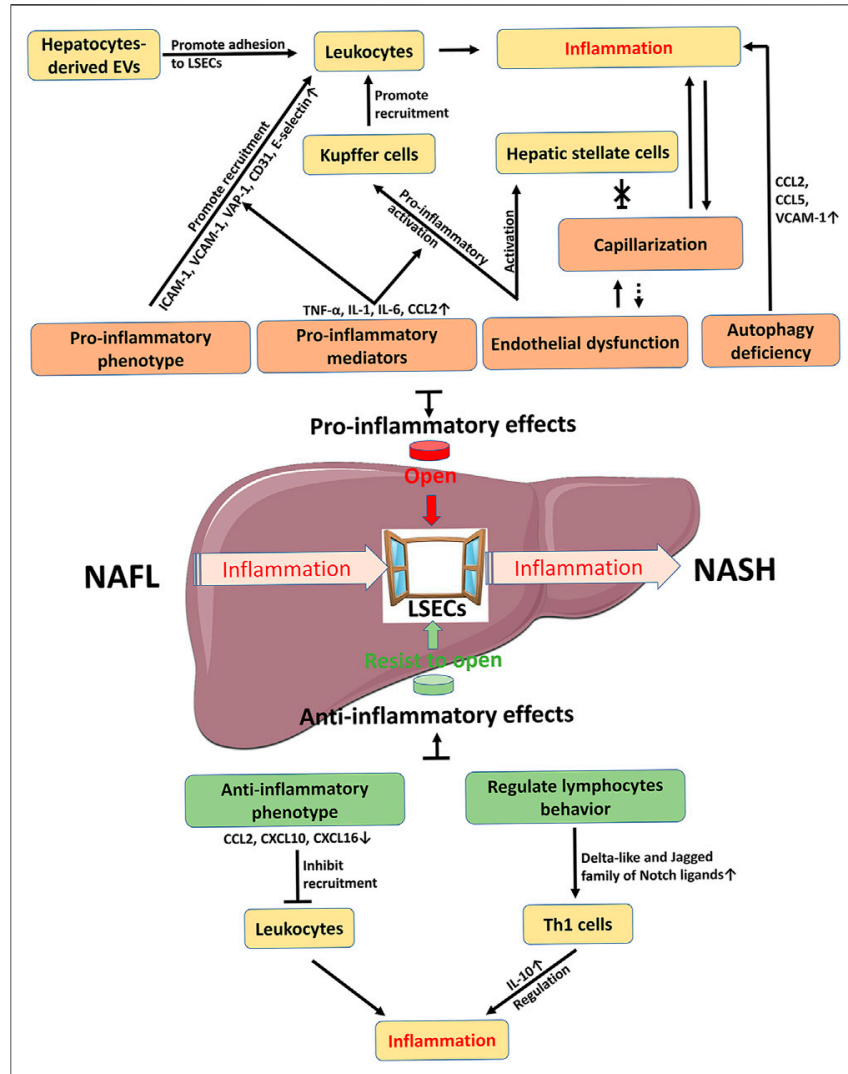

FIGURE 4 | Schematic summary on the role of LSECs in NAFLD inflammation. Inflammation is a key factor in the development of NAFL to $\mathrm{NASH}$. LSEC as a window controls the occurrence and progression of inflammation. The pro-inflammatory effect of LSECs promotes the opening of the window, while the anti-inflammatory effect of LSECs acts as an opponent to prevent the passage of inflammation. Therefore, how to control the window provides new strategies for the R\&D of novelty drugs against NAFLD/NASH. The dotted line is a possible relationship. CCL C-C motif chemokine ligand, CXCL C-X-C motif chemokine ligand, EVs extracellular vesicles, ICAM-1 intercellular adhesion molecule-1, IL interleukin, LSECs liver sinusoidal endothelial cells, NAFL, nonalcoholic fatty liver, NASH nonalcoholic steatohepatitis, TNF- $\alpha$ tumor necrosis factor- $\alpha$, VAP-1 vascular adhesion protein-1, VCAM-1 vascular cell adhesion molecule-1.

demonstrated that how LSECs switch their phenotype into antiinflammatory phenotype during the occurrence and development of NAFLD inflammation. On the other hand, LSECs can drive lymphocytes to down-regulate inflammation. Under inflammatory conditions, LSECs release Notch ligands and thereby facilitate Th1 cells to secrete IL-10, an anti-

\section{REFERENCES}

Adachi, H., and Tsujimoto, M. (2002). FEEL-1, a novel scavenger receptor with in vitro bacteria-binding and angiogenesis-modulating activities. J. Biol. Chem. 277 (37), 34264-34270. doi:10.1074/jbc.M204277200

Adams, D. H., Hubscher, S. G., Fisher, N. C., Williams, A., and Robinson, M. (1996). Expression of E-selectin and E-selectin ligands in human liver inflammation. Hepatol. 24 (3), 533-538. doi:10.1002/hep.510240311 inflammatory cytokine (Neumann et al., 2015). The clue indicates that effectively controlling the behavior of LSECs to indirectly regulate inflammation may be a potential research direction.

\section{CONCLUSION}

Under physiological conditions, LSECs have multiple functions due to their unique structure and anatomical position, including substance exchange and clearance, blood flow regulation, and immune regulation, and therefore LSECs contribute to the maintenance of liver homeostasis. In NAFLD, LSECs have dual roles in inflammation (Figures 2, 4). On one hand, LSECs block the occurrence of inflammation by generating anti-inflammatory phenotype and regulating lymphocyte behavior. On the other hand, LSECs show pro-inflammatory effects including promoting the activation of $\mathrm{KCs}$ and the recruitment of leukocytes. The detailed mechanisms are involved with multiple alterations of LSECs, including morphology and endothelial function, paracrine and autocrine signals, hepatocyte-derived EVs, and autophagy abnormalities. Accordingly, changing these abnormalities of LSECs with new drug candidates is an attractive therapeutic strategy to control inflammation in NAFLD/NASH by regulating LSECs via several variable factors, including adhesion molecules and chemokines expressed by LSECs, capillarization and endothelial dysfunction of LSECs, and other regulatory factors such as EVs. However, the current challenge in this research area is still to clarify the mechanism of LSEC alteration in NAFLD and to further validate the clinical efficacy with those drug candidates specifically targeted to LSEC-related molecules.

\section{AUTHOR CONTRIBUTIONS}

Both authors listed wrote the manuscript, edited the document, and approved it for publication.

\section{FUNDING}

This work was supported by CAMS Innovation Fund for Medical Sciences (grant number 2017-I2M-3-012); National MegaProject for "R\&D for Innovative drugs", Ministry of Science and Technology, China (grant number 2018ZX09711001003-010).

Ahsan, F., Oliveri, F., Goud, H. K., Mehkari, Z., Mohammed, L., Javed, M., et al (2020). Pleiotropic effects of statins in the light of non-alcoholic fatty liver disease and non-alcoholic steatohepatitis. Cureus 12 (9), e10446. doi:10.7759/ cureus.10446

Akyol, G., Erdem, O., and Yilmaz, G. (2005). Nonalcoholic fatty liver disease. Correlation with histology and viral hepatitis. Saudi Med. J. 26 (12), 1904-1910.

Allaire, M., Rautou, P.-E., Codogno, P., and Lotersztajn, S. (2019). Autophagy in liver diseases: time for translation?. J. Hepatol. 70 (5), 985-998. doi:10.1016/j. jhep.2019.01.026 
Arii, S., and Imamura, M. (2000). Physiological role of sinusoidal endothelial cells and Kupffer cells and their implication in the pathogenesis of liver injury. J. Hepato-Biliary-Pancreatic Surg. 7 (1), 40-48. doi:10.1007/s005340050152

Arrese, M., Cabrera, D., Kalergis, A. M., and Feldstein, A. E. (2016). Innate immunity and inflammation in NAFLD/NASH. Dig. Dis. Sci. 61 (5), 1294-1303. doi:10.1007/s10620-016-4049-x

Arteta, B., Lasuen, N., Lopategi, A., Sveinbjörnsson, B., Smedsrød, B., and VidalVanaclocha, F. (2010). Colon carcinoma cell interaction with liver sinusoidal endothelium inhibits organ-specific antitumor immunity through interleukin1-induced mannose receptor in mice. Hepatol. 51 (6), 2172-2182. doi:10.1002/ hep. 23590

Baffy, G. (2018). Origins of portal hypertension in nonalcoholic fatty liver disease. Dig. Dis. Sci. 63 (3), 563-576. doi:10.1007/s10620-017-4903-5

Baiocchini, A., Del Nonno, F., Taibi, C., Visco-Comandini, U., D’Offizi, G., Piacentini, M., et al. (2019). Liver sinusoidal endothelial cells (LSECs) modifications in patients with chronic hepatitis C. Sci. Rep. 9 (1), 8760. doi:10.1038/s41598-019-45114-1

Berg, M., Wingender, G., Djandji, D., Hegenbarth, S., Momburg, F., Hämmerling, G., et al. (2006). Cross-presentation of antigens from apoptotic tumor cells by liver sinusoidal endothelial cells leads to tumor-specific CD8+ T cell tolerance. Eur. J. Immunol. 36 (11), 2960-2970. doi:10.1002/eji.200636033

Bravo, M., Raurell, I., Hide, D., Fernández-Iglesias, A., Gil, M., Barberá, A., et al. (2019). Restoration of liver sinusoidal cell phenotypes by statins improves portal hypertension and histology in rats with NASH. Sci. Rep. 9 (1), 20183. doi:10.1038/s41598-019-56366-2

Brenner, C., Galluzzi, L., Kepp, O., and Kroemer, G. (2013). Decoding cell death signals in liver inflammation. J. Hepatol. 59 (3), 583-594. doi:10.1016/j.jhep. 2013.03.033

Brunt, E. M., Gouw, A. S. H., Hubscher, S. G., Tiniakos, D. G., Bedossa, P., Burt, A. D., et al. (2014). Pathology of the liver sinusoids. Histopathology 64 (7), 907-920. doi:10.1111/his.12364

Boehringer ingelheim (2019). Boehringer Ingelheim discontinues development of BI 1467335 for NASH Available at: http://www.pharmaxis.com.au/investor-centre/ news/view/boehringer-ingelheim-discontinues-development-of-bi-1467335for-nash (Accessed Dec 18, 2019).

Burgdorf, S., Kautz, A., Bohnert, V., Knolle, P. A., and Kurts, C. (2007). Distinct pathways of antigen uptake and intracellular routing in CD4 and CD8 T cell activation. Science 316 (5824), 612-616. doi:10.1126/science.1137971

Cai, J., Zhang, X. J., and Li, H. (2019). The role of innate immune cells in nonalcoholic steatohepatitis. Hepatol. 70 (3), 1026-1037. doi:10.1002/hep. 30506

Campbell, J. J., Hedrick, J., Zlotnik, A., Siani, M. A., Thompson, D. A., and Butcher, E. C. (1998). Chemokines and the arrest of lymphocytes rolling under flow conditions. Science 279 (5349), 381-384. doi:10.1126/science.279.5349.381

Canton, J., Neculai, D., and Grinstein, S. (2013). Scavenger receptors in homeostasis and immunity. Nat. Rev. Immunol. 13 (9), 621-634. doi:10. 1038/nri3515

Carambia, A., Freund, B., Schwinge, D., Heine, M., Laschtowitz, A., Huber, S., et al. (2014). TGF- $\beta$-dependent induction of CD4+CD25+Foxp3+ Tregs by liver sinusoidal endothelial cells. J. Hepatol. 61 (3), 594-599. doi:10.1016/j.jhep.2014. 04.027

Carpenter, B., Lin, Y., Stoll, S., Raffai, R. L., McCuskey, R., and Wang, R. (2005). VEGF is crucial for the hepatic vascular development required for lipoprotein uptake. Development 132 (14), 3293-3303. doi:10.1242/dev. 01902

Chauhan, S. D., Seggara, G., Vo, P. A., Macallister, R. J., Hobbs, A. J., and Ahluwalia, A. (2003). Protection against lipopolysaccharide-induced endothelial dysfunction in resistance and conduit vasculature of iNOS knockout mice. FASEB j. 17 (6), 773-775. doi:10.1096/fj.02-0668fje

Chen, G. Y., and Nuñez, G. (2010). Sterile inflammation: sensing and reacting to damage. Nat. Rev. Immunol. 10 (12), 826-837. doi:10.1038/nri2873

Chen, L., Gu, T., Li, B., Li, F., Ma, Z., Zhang, Q., et al. (2019). Delta-like ligand 4/ DLL4 regulates the capillarization of liver sinusoidal endothelial cell and liver fibrogenesis. Biochim. Biophys. Acta (Bba) - Mol. Cel Res. 1866 (10), 1663-1675. doi:10.1016/j.bbamcr.2019.06.011

Chiu, J.-J., and Chien, S. (2011). Effects of disturbed flow on vascular endothelium: pathophysiological basis and clinical perspectives. Physiol. Rev. 91 (1), 327-387. doi:10.1152/physrev.00047.2009
Choi, A. M., Ryter, S. W., and Levine, B. (2013). Autophagy in human health and disease. N. Engl. J. Med. 368 (19), 1845-1846. doi:10.1056/nejmc1303158

Cogger, V. C., Hilmer, S. N., Sullivan, D., Muller, M., Fraser, R., and Le Couteur, D. G. (2006). Hyperlipidemia and surfactants: the liver sieve is a link. Atherosclerosis 189 (2), 273-281. doi:10.1016/j.atherosclerosis.2005.12.025

Cogger, V. C., Mohamad, M., Solon-Biet, S. M., Senior, A. M., Warren, A., O’Reilly, J. N., et al. (2016). Dietary macronutrients and the aging liver sinusoidal endothelial cell. Am. J. Physiology-Heart Circulatory Physiol. 310 (9), H1064-H1070. doi:10.1152/ajpheart.00949.2015

Coulon, S., Francque, S., Colle, I., Verrijken, A., Blomme, B., Heindryckx, F., et al. (2012). Evaluation of inflammatory and angiogenic factors in patients with non-alcoholic fatty liver disease. Cytokine 59 (2), 442-449. doi:10.1016/j.cyto. 2012.05.001

Coulon, S., Heindryckx, F., Geerts, A., Van Steenkiste, C., Colle, I., and Van Vlierberghe, H. (2011). Angiogenesis in chronic liver disease and its complications. Liver Int. 31 (2), 146-162. doi:10.1111/j.1478-3231.2010. 02369.x

Coulon, S., Legry, V., Heindryckx, F., Van Steenkiste, C., Casteleyn, C., Olievier, K., et al. (2013). Role of vascular endothelial growth factor in the pathophysiology of nonalcoholic steatohepatitis in two rodent models. Hepatol. 57 (5), 1793-1805. doi:10.1002/hep.26219

Davies, P. F. (1995). Flow-mediated endothelial mechanotransduction. Physiol. Rev. 75 (3), 519-560. doi:10.1152/physrev.1995.75.3.519

DeLeve, L. D. (2015). Liver sinusoidal endothelial cells in hepatic fibrosis. Hepatol. 61 (5), 1740-1746. doi:10.1002/hep.27376

Deleve, L. D., Wang, X., and Guo, Y. (2008). Sinusoidal endothelial cells prevent rat stellate cell activation and promote reversion to quiescence. Hepatol. 48 (3), 920-930. doi:10.1002/hep.22351

DeLeve, L. D., Wang, X., Hu, L., McCuskey, M. K., and McCuskey, R. S. (2004). Rat liver sinusoidal endothelial cell phenotype is maintained by paracrine and autocrine regulation. Am. J. Physiology-Gastrointestinal Liver Physiol. 287 (4), G757-G763. doi:10.1152/ajpgi.00017.2004

Desroches-Castan, A., Tillet, E., Ricard, N., Ouarné, M., Mallet, C., Belmudes, L., et al. (2019). Bone morphogenetic protein 9 is a paracrine factor controlling liver sinusoidal endothelial cell fenestration and protecting against hepatic fibrosis. Hepatol. 70 (4), 1392-1408. doi:10.1002/hep.30655

Diehl, L., Schurich, A., Grochtmann, R., Hegenbarth, S., Chen, L., and Knolle, P. A. (2008). Tolerogenic maturation of liver sinusoidal endothelial cells promotes B7-homolog 1-dependent CD8+ T cell tolerance. Hepatol. 47 (1), 296-305. doi:10.1002/hep. 21965

Doulias, P.-T., Tenopoulou, M., Greene, J. L., Raju, K., and Ischiropoulos, H. (2013). Nitric oxide regulates mitochondrial fatty acid metabolism through reversible protein S-nitrosylation. Sci. Signaling 6 (256), rs1. doi:10.1126/ scisignal.2003252

Edwards, S., Lalor, P. F., Nash, G. B., Rainger, G. E., and Adams, D. H. (2005). Lymphocyte traffic through sinusoidal endothelial cells is regulated by hepatocytes. Hepatol. 41 (3), 451-459. doi:10.1002/hep.20585

Eguchi, A., and Feldstein, A. E. (2018). Extracellular vesicles in non-alcoholic and alcoholic fatty liver diseases. Liver Res. 2 (1), 30-34. doi:10.1016/j.livres.2018. 01.001

Eslam, M., Sanyal, A. J., George, J., Sanyal, A., Neuschwander-Tetri, B., Tiribelli, C., et al. (2020). MAFLD: a consensus-driven proposed nomenclature for metabolic associated fatty liver disease. Gastroenterol. 158 (7), 1999-2014. doi:10.1053/j.gastro.2019.11.312

Estes, C., Razavi, H., Loomba, R., Younossi, Z., and Sanyal, A. J. (2018). Modeling the epidemic of nonalcoholic fatty liver disease demonstrates an exponential increase in burden of disease. Hepatol. 67 (1), 123-133. doi: $10.1002 /$ hep. 29466

Fernandez, M. (2015). Molecular pathophysiology of portal hypertension. Hepatol. 61 (4), 1406-1415. doi:10.1002/hep.27343

Flammer, A. J., Anderson, T., Celermajer, D. S., Creager, M. A., Deanfield, J., Ganz, P., et al. (2012). The assessment of endothelial function. Circulation 126 (6), 753-767. doi:10.1161/circulationaha.112.093245

Ford, A. J., Jain, G., and Rajagopalan, P. (2015). Designing a fibrotic microenvironment to investigate changes in human liver sinusoidal endothelial cell function. Acta Biomater. 24, 220-227. doi:10.1016/j.actbio. 2015.06 .028 
Francque, S., Laleman, W., Verbeke, L., Van Steenkiste, C., Casteleyn, C., Kwanten, W., et al. (2012). Increased intrahepatic resistance in severe steatosis: endothelial dysfunction, vasoconstrictor overproduction and altered microvascular architecture. Lab. Invest. 92 (10), 1428-1439. doi:10.1038/ labinvest.2012.103

Friedman, S. L., Neuschwander-Tetri, B. A., Rinella, M., and Sanyal, A. J. (2018). Mechanisms of NAFLD development and therapeutic strategies. Nat. Med. 24 (7), 908-922. doi:10.1038/s41591-018-0104-9

Gadd, V. L., Skoien, R., Powell, E. E., Fagan, K. J., Winterford, C., Horsfall, L., et al. (2014). The portal inflammatory infiltrate and ductular reaction in human nonalcoholic fatty liver disease. Hepatol. 59 (4), 1393-1405. doi:10.1002/hep. 26937

Garcia-Martinez, I., Santoro, N., Chen, Y., Hoque, R., Ouyang, X., Caprio, S., et al. (2016). Hepatocyte mitochondrial DNA drives nonalcoholic steatohepatitis by activation of TLR9. J. Clin. Invest. 126 (3), 859-864. doi:10.1172/JCI83885

Géraud, C., Koch, P.-S., Zierow, J., Klapproth, K., Busch, K., Olsavszky, V., et al. (2017). GATA4-dependent organ-specific endothelial differentiation controls liver development and embryonic hematopoiesis. J. Clin. Invest. 127 (3), 1099-1114. doi:10.1172/JCI90086

Gonzalez-Paredes, F. J., Hernández Mesa, G., Morales Arraez, D., Marcelino Reyes, R., Abrante, B., Diaz-Flores, F., et al. (2016). Contribution of cyclooxygenase end products and oxidative stress to intrahepatic endothelial dysfunction in early non-alcoholic fatty liver disease. PLoS One 11 (5), e0156650, doi:10.1371/ journal.pone.0156650

Gouysse, G., Couvelard, A., Frachon, S., Bouvier, R., Nejjari, M., Dauge, M.-C., et al. (2002). Relationship between vascular development and vascular differentiation during liver organogenesis in humans. J. Hepatol. 37 (6), 730-740. doi:10.1016/ s0168-8278(02)00282-9

Gracia-Sancho, J., and Guixé-Muntet, S. (2018). The many-faced role of autophagy in liver diseases. J. Hepatol. 68 (3), 593-594. doi:10.1016/j.jhep.2017.09.015

Gual, P., Gilgenkrantz, H., and Lotersztajn, S. (2017). Autophagy in chronic liver diseases: the two faces of Janus. Am. J. Physiology-Cell Physiol. 312 (3), C263-C273. doi:10.1152/ajpcell.00295.2016

Guo, Q., Furuta, K., Lucien, F., Gutierrez Sanchez, L. H., Hirsova, P., Krishnan, A., et al. (2019). Integrin $\beta 1$-enriched extracellular vesicles mediate monocyte adhesion and promote liver inflammation in murine NASH. J. Hepatol. 71 (6), 1193-1205. doi:10.1016/j.jhep.2019.07.019

Hall, K. C., Bernier, S. G., Jacobson, S., Liu, G., Zhang, P. Y., Sarno, R., et al. (2019). sGC stimulator praliciguat suppresses stellate cell fibrotic transformation and inhibits fibrosis and inflammation in models of NASH. Proc. Natl. Acad. Sci. USA 116 (22), 11057-11062. doi:10.1073/pnas.1821045116

Hammoutene, A., Biquard, L., Lasselin, J., Kheloufi, M., Tanguy, M., Vion, A.-C., et al. (2020). A defect in endothelial autophagy occurs in patients with nonalcoholic steatohepatitis and promotes inflammation and fibrosis. J. Hepatol. 72 (3), 528-538. doi:10.1016/j.jhep.2019.10.028

Hammoutene, A., and Rautou, P.-E. (2019). Role of liver sinusoidal endothelial cells in non-alcoholic fatty liver disease. J. Hepatol. 70 (6), 1278-1291. doi:10. 1016/j.jhep.2019.02.012

Hang, T.-C., Lauffenburger, D. A., Griffith, L. G., and Stolz, D. B. (2012). Lipids promote survival, proliferation, and maintenance of differentiation of rat liver sinusoidal endothelial cells in vitro. Am. J. Physiology-Gastrointestinal Liver Physiol. 302 (3), G375-G388. doi:10.1152/ajpgi.00288.2011

Hansen, B., Longati, P., Elvevold, K., Nedredal, G., Schledzewski, K., Olsen, R., et al. (2005). Stabilin-1 and stabilin-2 are both directed into the early endocytic pathway in hepatic sinusoidal endothelium via interactions with clathrin/AP-2, independent of ligand binding. Exp. Cel Res. 303 (1), 160-173. doi:10.1016/j. yexcr.2004.09.017

Harrison, S. A., Goodman, Z., Jabbar, A., Vemulapalli, R., Younes, Z. H., Freilich, B., et al. (2020). A randomized, placebo-controlled trial of emricasan in patients with NASH and F1-F3 fibrosis. J. Hepatol. 72 (5), 816-827. doi:10.1016/j.jhep. 2019.11.024

Hebert, L. A. (1991). The clearance of immune complexes from the circulation of man and other primates. Am. J. Kidney Dis. 17 (3), 352-361. doi:10.1016/s02726386(12)80488-4

Hernández-Gea, V., Ghiassi-Nejad, Z., Rozenfeld, R., Gordon, R., Fiel, M. I., Yue, Z., et al. (2012). Autophagy releases lipid that promotes fibrogenesis by activated hepatic stellate cells in mice and in human tissues. Gastroenterol. 142 (4), 938-946. doi:10.1053/j.gastro.2011.12.044
Herrnberger, L., Hennig, R., Kremer, W., Hellerbrand, C., Goepferich, A., Kalbitzer, H. R., et al. (2014). Formation of fenestrae in murine liver sinusoids depends on plasmalemma vesicle-associated protein and is required for lipoprotein passage. PLoS One 9 (12), e115005, doi:10.1371/ journal.pone. 0115005

Hilmer, S. N., Cogger, V. C., Fraser, R., McLean, A. J., Sullivan, D., and Le Couteur, D. G. (2005). Age-related changes in the hepatic sinusoidal endothelium impede lipoprotein transfer in the rat. Hepatol. 42 (6), 1349-1354. doi:10. 1002/hep.20937

Hirsova, P., Ibrahim, S. H., Krishnan, A., Verma, V. K., Bronk, S. F., Werneburg, N. W., et al. (2016a). Lipid-induced signaling causes release of inflammatory extracellular vesicles from hepatocytes. Gastroenterol. 150 (4), 956-967. doi:10. 1053/j.gastro.2015.12.037

Hirsova, P., Ibrahim, S. H., Verma, V. K., Morton, L. A., Shah, V. H., LaRusso, N. F., et al. (2016b). Extracellular vesicles in liver pathobiology: small particles with big impact. Hepatol. 64 (6), 2219-2233. doi:10.1002/hep.28814

Horn, T., Christoffersen, P., and Henriksen, J. H. (1987). Alcoholic liver injury: defenestration in noncirrhotic livers-a scanning electron microscopic study. Hepatol. 7 (1), 77-82. doi:10.1002/hep.1840070117

Hughes, D. A., Fraser, I. P., and Gordon, S. (1995). Murine macrophage scavenger receptor:in vivo expression and function as receptor for macrophage adhesion in lymphoid and non-lymphoid organs. Eur. J. Immunol. 25 (2), 466-473. doi:10.1002/eji.1830250224

Hunt, N. J., Kang, S. W., Lockwood, G. P., Le Couteur, D. G., and Cogger, V. C. (2019). Hallmarks of aging in the liver. Comput. Struct. Biotechnol. J. 17, 1151-1161. doi:10.1016/j.csbj.2019.07.021

Ibrahim, S. H., Hirsova, P., Tomita, K., Bronk, S. F., Werneburg, N. W., Harrison, S. A., et al. (2016). Mixed lineage kinase 3 mediates release of $\mathrm{C}-\mathrm{X}-\mathrm{C}$ motif ligand 10-bearing chemotactic extracellular vesicles from lipotoxic hepatocytes. Hepatol. 63 (3), 731-744. doi:10.1002/hep.28252

Iwakiri, Y., Shah, V., and Rockey, D. C. (2014). Vascular pathobiology in chronic liver disease and cirrhosis - current status and future directions. J. Hepatol. 61 (4), 912-924. doi:10.1016/j.jhep.2014.05.047

Johansson, A. G., Lövdal, T., Magnusson, K., Berg, T., and Skogh, T. (1996). Liver cell uptake and degradation of soluble immunoglobulin $\mathrm{G}$ immune complexesin vivoandin vitroin rats. Hepatol. 24 (1), 169-175. doi:10.1002/ hep.510240128

John, M., Kim, K.-J., Bae, S. D. W., Qiao, L., and George, J. (2019). Role of BMP-9 in human liver disease. Gut 68 (11), 2097-2100. doi:10.1136/gutjnl-2018317543

Kakazu, E., Mauer, A. S., Yin, M., and Malhi, H. (2016). Hepatocytes release ceramide-enriched pro-inflammatory extracellular vesicles in an IRE1adependent manner. J. Lipid Res. 57 (2), 233-245. doi:10.1194/jlr.M063412

Kitade, M., Yoshiji, H., Kojima, H., Ikenaka, Y., Noguchi, R., Kaji, K., et al. (2008). Neovascularization and oxidative stress in the progression of non-alcoholic steatohepatitis. Mol. Med. Rep. 1 (4), 543-548. doi:10.3892/mmr.1.4.543

Kitade, M., Yoshiji, H., Noguchi, R., Ikenaka, Y., Kaji, K., Shirai, Y., et al. (2009). Crosstalk between angiogenesis, cytokeratin-18, and insulinresistance in the progression of non-alcoholic steatohepatitis. Wjg 15 (41), 5193-5199. doi:10. 3748/wjg.15.5193

Knolle, P. A., Uhrig, A., Hegenbarth, S., LÖser, E., Schmitt, E., Gerken, G., et al. (1998). IL-10 down-regulates $\mathrm{T}$ cell activation by antigen-presenting liver sinusoidal endothelial cells through decreased antigen uptake via the mannose receptor and lowered surface expression of accessory molecules. Clin. Exp. Immunol. 114 (3), 427-433. doi:10.1046/j.1365-2249.1998.00713.x

Knolle, P., Schmitt, E., Jin, S., Germann, T., Duchmann, R., Hegenbarth, S., et al. (1999). Induction of cytokine production in naive CD4+ T cells by antigenpresenting murine liver sinusoidal endothelial cells but failure to induce differentiation toward Th1 cells. Gastroenterol. 116 (6), 1428-1440. doi:10. 1016/s0016-5085(99)70508-1

Kodama, K., Toda, K., Morinaga, S., Yamada, S., and Butte, A. J. (2015). Anti-CD44 antibody treatment lowers hyperglycemia and improves insulin resistance, adipose inflammation, and hepatic steatosis in diet-induced obese mice. Diabetes 64 (3), 867-875. doi:10.2337/db14-0149

Koyama, Y., and Brenner, D. A. (2017). Liver inflammation and fibrosis. J. Clin. Invest. 127 (1), 55-64. doi:10.1172/JCI88881

Kubes, P., and Jenne, C. (2018). Immune responses in the liver. Annu. Rev. Immunol. 36, 247-277. doi:10.1146/annurev-immunol-051116-052415 
Kus, E., Kaczara, P., Czyzynska-Cichon, I., Szafranska, K., Zapotoczny, B., Kij, A., et al. (2019). LSEC fenestrae are preserved despite pro-inflammatory phenotype of liver sinusoidal endothelial cells in mice on high fat diet. Front. Physiol. 10, 6. doi:10.3389/fphys.2019.00006

Lanthier, N. (2015). Targeting Kupffer cells in non-alcoholic fatty liver disease/ non-alcoholic steatohepatitis: why and how?. Wjh 7 (19), 2184-2188. doi:10. 4254/wjh.v7.i19.2184

Lee, S. J., Evers, S., Roeder, D., Parlow, A. F., Risteli, J., Risteli, L., et al. (2002). Mannose receptor-mediated regulation of serum glycoprotein homeostasis. Science 295 (5561), 1898-1901. doi:10.1126/science.1069540

Lefere, S., Van de Velde, F., Hoorens, A., Raevens, S., Van Campenhout, S., Vandierendonck, A., et al. (2019). Angiopoietin-2 promotes pathological angiogenesis and is a therapeutic target in murine nonalcoholic fatty liver disease. Hepatol. 69 (3), 1087-1104. doi:10.1002/hep.30294

Leroux, A., Ferrere, G., Godie, V., Cailleux, F., Renoud, M.-L., Gaudin, F., et al. (2012). Toxic lipids stored by Kupffer cells correlates with their proinflammatory phenotype at an early stage of steatohepatitis. J. Hepatol. 57 (1), 141-149. doi:10.1016/j.jhep.2012.02.028

Limmer, A., Ohl, J., Kurts, C., Ljunggren, H.-G., Reiss, Y., Groettrup, M., et al. (2000). Efficient presentation of exogenous antigen by liver endothelial cells to CD8+ T cells results in antigen-specific T-cell tolerance. Nat. Med. 6 (12), 1348-1354. doi:10.1038/82161

Limmer, A., Ohl, J., Wingender, G., Berg, M., Jüngerkes, F., Schumak, B., et al. (2005). Cross-presentation of oral antigens by liver sinusoidal endothelial cells leads to CD8 T cell tolerance. Eur. J. Immunol. 35 (10), 2970-2981. doi:10.1002/ eji.200526034

Lodder, J., Denaës, T., Chobert, M.-N., Wan, J., El-Benna, J., Pawlotsky, J.-M., et al. (2015). Macrophage autophagy protects against liver fibrosis in mice. Autophagy 11 (8), 1280-1292. doi:10.1080/15548627.2015.1058473

Loomba, R., Lawitz, E., Mantry, P. S., Jayakumar, S., Caldwell, S. H., Arnold, H., et al. (2018). The ASK1 inhibitor selonsertib in patients with nonalcoholic steatohepatitis: a randomized, phase 2 trial. Hepatol. 67 (2), 549-559. doi:10. 1002/hep. 29514

Madrigal-Matute, J., and Cuervo, A. M. (2016). Regulation of liver metabolism by autophagy. Gastroenterol. 150 (2), 328-339. doi:10. 1053/j.gastro.2015.09.042

Malerød, L., Juvet, L., Gjøen, T., and Berg, T. (2002). The expression of scavenger receptor class B, type I (SR-BI) and caveolin-1 in parenchymal and nonparenchymal liver cells. Cell Tissue Res. 307 (2), 173-180. doi:10.1007/ s00441-001-0476-9

Maslak, E., Gregorius, A., and Chlopicki, S. (2015a). Liver sinusoidal endothelial cells (LSECs) function and NAFLD; NO-based therapy targeted to the liver. Pharmacol. Rep. 67 (4), 689-694. doi:10.1016/j.pharep.2015.04.010

Maslak, E., Zabielski, P., Kochan, K., Kus, K., Jasztal, A., Sitek, B., et al. (2015b). The liver-selective NO donor, V-PYRRO/NO, protects against liver steatosis and improves postprandial glucose tolerance in mice fed high fat diet. Biochem. Pharmacol. 93 (3), 389-400. doi:10.1016/j.bcp.2014.12.004

McCourt, P. A. G., Smedsrød, B. H., Melkko, J., and Johansson, S. (1999). Characterization of a hyaluronan receptor on rat sinusoidal liver endothelial cells and its functional relationship to scavenger receptors. Hepatol. 30 (5), 1276-1286. doi:10.1002/hep.510300521

McDonald, B., and Kubes, P. (2015). Interactions between CD44 and hyaluronan in leukocyte trafficking. Front. Immunol. 6, 68. doi:10.3389/fimmu.2015.00068

McDonald, B., McAvoy, E. F., Lam, F., Gill, V., de la Motte, C., Savani, R. C., et al. (2008). Interaction of CD44 and hyaluronan is the dominant mechanism for neutrophil sequestration in inflamed liver sinusoids. J. Exp. Med. 205 (4), 915-927. doi:10.1084/jem.20071765

McEver, R. P. (2015). Selectins: initiators of leucocyte adhesion and signalling at the vascular wall. Cardiovasc. Res. 107 (3), 331-339. doi:10.1093/cvr/cvv154

McGreal, E., Martinezpomares, L., and Gordon, S. (2004). Divergent roles for C-type lectins expressed by cells of the innate immune system. Mol. Immunol. 41 (11), 1109-1121. doi:10.1016/j.molimm.2004.06.013

McMahan, R. H., Porsche, C. E., Edwards, M. G., and Rosen, H. R. (2016). Free fatty acids differentially downregulate chemokines in liver sinusoidal endothelial cells: insights into non-alcoholic fatty liver disease. PLoS One 11 (7), e0159217, doi:10.1371/journal.pone.0159217

Miller, A. M., Wang, H., Park, O., Horiguchi, N., Lafdil, F., Mukhopadhyay, P., et al. (2010). Anti-inflammatory and anti-apoptotic roles of endothelial cell STAT3 in alcoholic liver injury. Alcohol. Clin. Exp. Res. 34 (4), 719-725. doi:10.1111/j. 1530-0277.2009.01141.x

Miura, K., Yang, L., van Rooijen, N., Ohnishi, H., and Seki, E. (2012). Hepatic recruitment of macrophages promotes nonalcoholic steatohepatitis through CCR2. Am. J. Physiology-Gastrointestinal Liver Physiol. 302 (11), G1310-G1321. doi:10.1152/ajpgi.00365.2011

Miyachi, Y., Tsuchiya, K., Komiya, C., Shiba, K., Shimazu, N., Yamaguchi, S., et al. (2017). Roles for cell-cell adhesion and contact in obesity-induced hepatic myeloid cell accumulation and glucose intolerance. Cel Rep. 18 (11), 2766-2779. doi:10.1016/j.celrep.2017.02.039

Miyao, M., Kotani, H., Ishida, T., Kawai, C., Manabe, S., Abiru, H., et al. (2015). Pivotal role of liver sinusoidal endothelial cells in NAFLD/NASH progression. Lab. Invest. 95 (10), 1130-1144. doi:10.1038/labinvest.2015.95

Mönkemöller, V., Øie, C., Hübner, W., Huser, T., and McCourt, P. (2015). Multimodal super-resolution optical microscopy visualizes the close connection between membrane and the cytoskeleton in liver sinusoidal endothelial cell fenestrations. Sci. Rep. 5, 16279. doi:10.1038/srep16279

Mousavi, S. A., Sporstøl, M., Fladeby, C., Kjeken, R., Barois, N., and Berg, T. (2007). Receptor-mediated endocytosis of immune complexes in rat liver sinusoidal endothelial cells is mediated by Fc $\gamma$ RIIb2. Hepatol. 46 (3), 871-884. doi:10. 1002/hep. 21748

Muller, W. A. (2016). Transendothelial migration: unifying principles from the endothelial perspective. Immunol. Rev. 273 (1), 61-75. doi:10.1111/imr.12443

Nati, M., Haddad, D., Birkenfeld, A. L., Koch, C. A., Chavakis, T., and Chatzigeorgiou, A. (2016). The role of immune cells in metabolism-related liver inflammation and development of non-alcoholic steatohepatitis (NASH). Rev. Endocr. Metab. Disord. 17 (1), 29-39. doi:10.1007/s11154-016-9339-2

Navarra, T., Del Turco, S., Berti, S., and Basta, G. (2010). The lectin-like oxidized low-density lipoprotein receptor-1 and its soluble form: cardiovascular implications. Jat 17 (4), 317-331. doi:10.5551/jat.3228

Neumann, K., Rudolph, C., Neumann, C., Janke, M., Amsen, D., and Scheffold, A. (2015). Liver sinusoidal endothelial cells induce immunosuppressive IL-10producing Th1 cells via the Notch pathway. Eur. J. Immunol. 45 (7), 2008-2016. doi:10.1002/eji.201445346

Nourshargh, S., and Alon, R. (2014). Leukocyte migration into inflamed tissues. Immunity 41 (5), 694-707. doi:10.1016/j.immuni.2014.10.008

O'Reilly, J. N., Cogger, V. C., Fraser, R., and Le Couteur, D. G. (2010). The effect of feeding and fasting on fenestrations in the liver sinusoidal endothelial cell. Pathol. 42 (3), 255-258. doi:10.3109/00313021003636469

Ozturk, O., Colak, Y., Senates, E., Yilmaz, Y., Ulasoglu, C., Doganay, L., et al. (2015). Increased serum soluble lectin-like oxidized low-density lipoprotein receptor-1 levels in patients with biopsy-proven nonalcoholic fatty liver disease. Wjg 21 (26), 8096-8102. doi:10.3748/wjg.v21.i26.8096

Parmar, K. M., Larman, H. B., Dai, G., Zhang, Y., Wang, E. T., Moorthy, S. N., et al. (2006). Integration of flow-dependent endothelial phenotypes by Kruppel-like factor 2. J. Clin. Invest. 116 (1), 49-58. doi:10.1172/JCI24787

Pasarín, M., Abraldes, J. G., Liguori, E., Kok, B., and Mura, V. L. (2017). Intrahepatic vascular changes in non-alcoholic fatty liver disease: potential role of insulin-resistance and endothelial dysfunction. Wjg 23 (37), 6777-6787. doi:10.3748/wjg.v23.i37.6777

Pasarín, M., Abraldes, J. G., Rodríguez-Vilarrupla, A., La Mura, V., García-Pagán, J. C., and Bosch, J. (2011). Insulin resistance and liver microcirculation in a rat model of early NAFLD. J. Hepatol. 55 (5), 1095-1102. doi:10.1016/j.jhep.2011. 01.053

Pasarín, M., La Mura, V., Gracia-Sancho, J., García-Calderó, H., RodríguezVilarrupla, A., García-Pagán, J. C., et al. (2012). Sinusoidal endothelial dysfunction precedes inflammation and fibrosis in a model of NAFLD. PLoS One 7 (4), e32785, doi:10.1371/journal.pone.0032785

Peng, Q., Zhang, Q., Xiao, W., Shao, M., Fan, Q., Zhang, H., et al. (2014). Protective effects of Sapindus mukorossi Gaertn against fatty liver disease induced by high fat diet in rats. Biochem. Biophysical Res. Commun. 450 (1), 685-691. doi:10. 1016/j.bbrc.2014.06.035

Pi, X., Xie, L., and Patterson, C. (2018). Emerging roles of vascular endothelium in metabolic homeostasis. Circ. Res. 123 (4), 477-494. doi:10.1161/ CIRCRESAHA.118.313237

Poisson, J., Lemoinne, S., Boulanger, C., Durand, F., Moreau, R., Valla, D., et al. (2017). Liver sinusoidal endothelial cells: physiology and role in liver diseases. J. Hepatol. 66 (1), 212-227. doi:10.1016/j.jhep.2016.07.009 
Politz, O., Gratchev, A., McCourt, P. A. G., Schledzewski, K., Guillot, P., Johansson, S., et al. (2002). Stabilin-1 and -2 constitute a novel family of fasciclin-like hyaluronan receptor homologues. Biochem. J. 362 (Pt 1), 155-164. doi:10.1042/ 0264-6021:3620155

Potente, M., and Mäkinen, T. (2017). Vascular heterogeneity and specialization in development and disease. Nat. Rev. Mol. Cel Biol. 18 (8), 477-494. doi:10.1038/ nrm.2017.36

Pourhoseini, S., Seth, R. K., Das, S., Dattaroy, D., Kadiiska, M. B., Xie, G., et al. (2015). Upregulation of miR21 and repression of Grhl3 by leptin mediates sinusoidal endothelial injury in experimental nonalcoholic steatohepatitis. PLoS One 10 (2), e0116780. doi:10.1371/journal.pone. 0116780

Ratziu, V., Sanyal, A., Harrison, S. A., Wong, V. W. S., Francque, S., Goodman, Z., et al. (2020). Cenicriviroc treatment for adults with nonalcoholic steatohepatitis and fibrosis: final analysis of the phase $2 \mathrm{~b}$ centaur study. Hepatol. 72 (3), 892-905. doi:10.1002/hep.31108

Rieder, H., Ramadori, G., and Meyer zum Büschenfelde, K. H. (1991). Sinusoidal endothelial liver cells in vitro release endothelin - augmentation by transforming growth factor $\beta$ and Kupffer cell-conditioned media. Klin Wochenschr 69 (9), 387-391. doi:10.1007/bf01647411

Rinella, M. E. (2015). Nonalcoholic fatty liver disease. JAMA 313 (22), 2263-2273. doi:10.1001/jama.2015.5370

Roediger, W., Hems, R., Wiggins, D., and Gibbons, G. (2004). Inhibition of hepatocyte lipogenesis by nitric oxide donor: could nitric oxide regulate lipid synthesis?. IUBMB Life (International Union Biochem. Mol. Biol. Life) 56 (1), 35-40. doi:10.1080/15216540310001649822

Roh, Y.-S., and Seki, E. (2018). Chemokines and chemokine receptors in the development of NAFLD. Adv. Exp. Med. Biol. 1061, 45-53. doi:10.1007/978981-10-8684-7_4

Romero, F. A., Jones, C. T., Xu, Y., Fenaux, M., and Halcomb, R. L. (2020). The race to bash NASH: emerging targets and drug development in a complex liver disease. J. Med. Chem. 63 (10), 5031-5073. doi:10.1021/acs.jmedchem. $9 \mathrm{~b} 01701$

Ruart, M., Chavarria, L., Campreciós, G., Suárez-Herrera, N., Montironi, C., GuixéMuntet, S., et al. (2019). Impaired endothelial autophagy promotes liver fibrosis by aggravating the oxidative stress response during acute liver injury. J. Hepatol. 70 (3), 458-469. doi:10.1016/j.jhep.2018.10.015

Sawada, K., Ohtake, T., Hasebe, T., Abe, M., Tanaka, H., Ikuta, K., et al. (2014). Augmented hepatic Toll-like receptors by fatty acids trigger the proinflammatory state of non-alcoholic fatty liver disease in mice. Hepatol. Res. 44 (8), 920-934. doi:10.1111/hepr.12199

Schaffner, F., and Popper, H. (1963). Capillarization of hepatic sinusoids in man. Gastroenterol. 44, 239-242. doi:10.1016/s0016-5085(63)80130-4

Schild, L., Dombrowski, F., Lendeckel, U., Schulz, C., Gardemann, A., and Keilhoff, G. (2008). Impairment of endothelial nitric oxide synthase causes abnormal fat and glycogen deposition in liver. Biochim. Biophys. Acta (Bba) - Mol. Basis Dis. 1782 (3), 180-187. doi:10.1016/j.bbadis.2007.12.007

Schuster, S., Cabrera, D., Arrese, M., and Feldstein, A. E. (2018). Triggering and resolution of inflammation in NASH. Nat. Rev. Gastroenterol. Hepatol. 15 (6), 349-364. doi:10.1038/s41575-018-0009-6

Schwabe, R. F., Tabas, I., and Pajvani, U. B. (2020). Mechanisms of fibrosis development in nonalcoholic steatohepatitis. Gastroenterol. 158 (7), 1913-1928. doi:10.1053/j.gastro.2019.11.311

Shah, V., Haddad, F. G., Garcia-Cardena, G., Frangos, J. A., Mennone, A., Groszmann, R. J., et al. (1997). Liver sinusoidal endothelial cells are responsible for nitric oxide modulation of resistance in the hepatic sinusoids. J. Clin. Invest. 100 (11), 2923-2930. doi:10.1172/JCI119842

Shetty, S., Lalor, P. F., and Adams, D. H. (2018). Liver sinusoidal endothelial cells gatekeepers of hepatic immunity. Nat. Rev. Gastroenterol. Hepatol. 15 (9), 555-567. doi:10.1038/s41575-018-0020-y

Smedsrød, B., Le Couteur, D., Ikejima, K., Jaeschke, H., Kawada, N., Naito, M., et al. (2009). Hepatic sinusoidal cells in health and disease: update from the 14th International Symposium. Liver Int. 29 (4), 490-501. doi:10.1111/j.1478-3231. 2009.01979.x

Sørensen, K. K., McCourt, P., Berg, T., Crossley, C., Couteur, D. L., Wake, K., et al. (2012). The scavenger endothelial cell: a new player in homeostasis and immunity. Am. J. Physiology-Regulatory, Integr. Comp. Physiol. 303 (12), R1217-R1230. doi:10.1152/ajpregu.00686.2011
Stahl, P. D., and Ezekowitz, R. A. B. (1998). The mannose receptor is a pattern recognition receptor involved in host defense. Curr. Opin. Immunol. 10 (1), 50-55. doi:10.1016/s0952-7915(98)80031-9

Stefan, N., Häring, H.-U., and Cusi, K. (2019). Non-alcoholic fatty liver disease: causes, diagnosis, cardiometabolic consequences, and treatment strategies. Lancet Diabetes Endocrinol. 7 (4), 313-324. doi:10.1016/S2213-8587(18)30154-2

Straub, A. C., Stolz, D. B., Vin, H., Ross, M. A., Soucy, N. V., Klei, L. R., et al. (2007). Low level arsenic promotes progressive inflammatory angiogenesis and liver blood vessel remodeling in mice. Toxicol. Appl. Pharmacol. 222 (3), 327-336. doi:10.1016/j.taap.2006.10.011

Tamaki, Y., Nakade, Y., Yamauchi, T., Makino, Y., Yokohama, S., Okada, M., et al. (2013). Angiotensin II type 1 receptor antagonist prevents hepatic carcinoma in rats with nonalcoholic steatohepatitis. J. Gastroenterol. 48 (4), 491-503. doi:10. 1007/s00535-012-0651-7

Tanaka, M., and Iwakiri, Y. (2016). The hepatic lymphatic vascular system: structure, function, markers, and lymphangiogenesis. Cell Mol. Gastroenterol. Hepatol. 2 (6), 733-749. doi:10.1016/j.jcmgh.2016.09.002

Tanaka, Y., Adams, D. H., Hubscher, S., Hirano, H., Siebenlist, U., and Shaw, S. (1993). T-cell adhesion induced by proteoglycan-immobilized cytokine MIP-1 $\beta$. Nature 361 (6407), 79-82. doi:10.1038/361079a0

Tateya, S., Rizzo, N. O., Handa, P., Cheng, A. M., Morgan-Stevenson, V., Daum, G., et al. (2011). Endothelial NO/cGMP/VASP signaling attenuates Kupffer cell activation and hepatic insulin resistance induced by high-fat feeding. Diabetes 60 (11), 2792-2801. doi:10.2337/db11-0255

Terns Pharmaceuticals (2019). TERNS pharmaceuticals announces positive interim results from ongoing phase 1 clinical trial of TERB-201, a SSAO inhibitor in development for NASH Available at: https://www.ternspharma.com/8-13-19terns-announces-positive-interim-results-from-ongoing-phase-1-clinical-trialof-tern-201 (Accessed August 13, 2019).

Villanova, N., Moscatiello, S., Ramilli, S., Bugianesi, E., Magalotti, D., Vanni, E., et al. (2005). Endothelial dysfunction and cardiovascular risk profile in nonalcoholic fatty liver disease. Hepatol. 42 (2), 473-480. doi:10.1002/hep.20781

Wang, W., Zhao, C., Zhou, J., Zhen, Z., Wang, Y., and Shen, C. (2013). Simvastatin ameliorates liver fibrosis via mediating nitric oxide synthase in rats with nonalcoholic steatohepatitis-related liver fibrosis. PLoS One 8 (10), e76538, doi:10. 1371/journal.pone.0076538

Warren, A., Bertolino, P., Benseler, V., Fraser, R., McCaughan, G. W., and Le Couteur, D. G. (2007). Marked changes of the hepatic sinusoid in a transgenic mouse model of acute immune-mediated hepatitis. J. Hepatol. 46 (2), 239-246. doi:10.1016/j.jhep.2006.08.022

Weston, C. J., Shepherd, E. L., Claridge, L. C., Rantakari, P., Curbishley, S. M., Tomlinson, J. W., et al. (2015). Vascular adhesion protein-1 promotes liver inflammation and drives hepatic fibrosis. J. Clin. Invest. 125 (2), 501-520. doi:10.1172/JCI73722

Wisse, E., De Zanger, R. B., Charels, K., Van Der Smissen, P., and McCuskey, R. S. (1985). The liver sieve: considerations concerning the structure and function of endothelial fenestrae, the sinusoidal wall and the space of Disse. Hepatol. 5 (4), 683-692. doi:10.1002/hep.1840050427

Wong, J., Johnston, B., Lee, S. S., Bullard, D. C., Smith, C. W., Beaudet, A. L., et al. (1997). A minimal role for selectins in the recruitment of leukocytes into the inflamed liver microvasculature. J. Clin. Invest. 99 (11), 2782-2790. doi:10. 1172/JCI1 19468

Wong, R. J., Aguilar, M., Cheung, R., Perumpail, R. B., Harrison, S. A., Younossi, Z. M., et al. (2015). Nonalcoholic steatohepatitis is the second leading etiology of liver disease among adults awaiting liver transplantation in the United States. Gastroenterol. 148 (3), 547-555. doi:10.1053/j.gastro.2014.11.039

Wu, J., Meng, Z., Jiang, M., Zhang, E., Trippler, M., Broering, R., et al. (2010). Tolllike receptor-induced innate immune responses in non-parenchymal liver cells are cell type-specific. Immunol. 129 (3), 363-374. doi:10.1111/j.1365-2567. 2009.03179.x

Xie, G., Choi, S. S., Syn, W.-K., Michelotti, G. A., Swiderska, M., Karaca, G., et al. (2013). Hedgehog signalling regulates liver sinusoidal endothelial cell capillarisation. Gut 62 (2), 299-309. doi:10.1136/gutjnl-2011-301494

Xie, G., Wang, L., Wang, X., Wang, L., and DeLeve, L. D. (2010). Isolation of periportal, midlobular, and centrilobular rat liver sinusoidal endothelial cells enables study of zonated drug toxicity. Am. J. PhysiologyGastrointestinal Liver Physiol. 299 (5), G1204-G1210. doi:10.1152/ ajpgi.00302.2010 
Xing, Y., Zhao, T., Gao, X., and Wu, Y. (2016). Liver X receptor $\alpha$ is essential for the capillarization of liver sinusoidal endothelial cells in liver injury. Sci. Rep. 6, 21309. doi:10.1038/srep21309

Xu, B., Broome, U., Uzunel, M., Nava, S., Ge, X., Kumagai-Braesch, M., et al. (2003). Capillarization of hepatic sinusoid by liver endothelial cell-reactive autoantibodies in patients with cirrhosis and chronic hepatitis. Am. J. Pathol. 163 (4), 1275-1289. doi:10.1016/S0002-9440(10)63487-6

Xu, M., Xu, H.-H., Lin, Y., Sun, X., Wang, L.-J., Fang, Z.-P., et al. (2019). LECT2, a ligand for Tie1, plays a crucial role in liver fibrogenesis. Cell 178 (6), 1478-1492. doi:10.1016/j.cell.2019.07.021

Yoshiji, H., Kuriyama, S., Noguchi, R., Ikenaka, Y., Kitade, M., Kaji, K., et al. (2006). Angiotensin-II and vascular endothelial growth factor interaction plays an important role in rat liver fibrosis development. Hepatol. Res. 36 (2), 124-129. doi:10.1016/j.hepres.2006.07.003

Younossi, Z. M., Koenig, A. B., Abdelatif, D., Fazel, Y., Henry, L., and Wymer, M. (2016). Global epidemiology of nonalcoholic fatty liver disease-Meta-analytic assessment of prevalence, incidence, and outcomes. Hepatol. 64 (1), 73-84. doi:10.1002/hep.28431

Younossi, Z. M. (2019). Non-alcoholic fatty liver disease - a global public health perspective. J. Hepatol. 70 (3), 531-544. doi:10.1016/j.jhep.2018.10.033

Zannetti, C., Roblot, G., Charrier, E., Ainouze, M., Tout, I., Briat, F., et al. (2016). Characterization of the inflammasome in human kupffer cells in response to synthetic agonists and pathogens. J.I. 197 (1), 356-367. doi:10.4049/jimmunol. 1502301

Zapotoczny, B., Szafranska, K., Kus, E., Braet, F., Wisse, E., Chlopicki, S., et al. (2019). Tracking fenestrae dynamics in live murine liver sinusoidal endothelial cells. Hepatol. 69 (2), 876-888. doi:10.1002/hep.30232
Zeng, X.-Q., Li, N., Pan, D.-Y., Miao, Q., Ma, G.-F., Liu, Y.-M., et al. (2015). Kruppel-like factor 2 inhibit the angiogenesis of cultured human liver sinusoidal endothelial cells through the ERK1/2 signaling pathway. Biochem. Biophysical Res. Commun. 464 (4), 1241-1247. doi:10.1016/j. bbrc.2015.07.113

Zhang, Q., Liu, J., Liu, J., Huang, W., Tian, L., Quan, J., et al. (2014). oxLDL induces injury and defenestration of human liver sinusoidal endothelial cells via LOX1. J. Mol. Endocrinol. 53 (2), 281-293. doi:10.1530/JME-140049

Zhang, Q., Yu, J., Guo, T., Tian, L., Quan, J., Lin, W., et al. (2019). High glucose/oxLDL induced hepatic sinusoidal capillarization via av $\beta 5 / F A K / E R K$ signaling pathway. Biochem. Biophysical Res. Commun. 513 (4), 1055-1062. doi:10.1016/ j.bbrc.2019.04.082

Zhou, B., Weigel, J. A., Fauss, L., and Weigel, P. H. (2000). Identification of the hyaluronan receptor for endocytosis (HARE). J. Biol. Chem. 275 (48), 37733-37741. doi:10.1074/jbc.M003030200

Conflict of Interest: The authors declare that the research was conducted in the absence of any commercial or financial relationships that could be construed as a potential conflict of interest.

Copyright $\odot 2021$ Wang and Peng. This is an open-access article distributed under the terms of the Creative Commons Attribution License (CC BY). The use, distribution or reproduction in other forums is permitted, provided the original author(s) and the copyright owner(s) are credited and that the original publication in this journal is cited, in accordance with accepted academic practice. No use, distribution or reproduction is permitted which does not comply with these terms. 